\title{
A test of the detection range of acoustic transmitters and receivers deployed in deep waters of Southeast Alaska, USA
}

\author{
Timothy Loher ${ }^{r^{*}}$ (D) Raymond A. Webster ${ }^{1}$ and David Carlile ${ }^{2}$
}

\begin{abstract}
Background: Movement data represent important inputs to both numerical and conceptual models that contribute to the assessment and management of sablefish (Anoplopoma fimbria) and Pacific halibut (Hippoglossus stenolepis) in the eastern North Pacific. While conventional mark-recovery data have greatly increased our understanding of these populations, tagging methods that produce only endpoint data (i.e., locations at tagging and recapture) cannot address dynamics such as the timing, frequency, and recurrence of movements. As a preliminary step in evaluating the feasibility of using acoustic biotelemetry for addressing management-relevant questions for relatively deepwater ( $\leq 600 \mathrm{~m}$ depth) species, we conducted tests of the detection range between VEMCO V16-5H transmitters and VR2W receivers. Six range-test stations were established that varied from a relatively shallow (154 m), narrow (3.8 km) ocean pass; through the mouth of a wide $(20 \mathrm{~km})$, deep $(600+\mathrm{m})$ fjord; and over the continental shelf. Each station consisted of one receiver mooring and five transmitter moorings deployed at regular distances from 200 to $1200 \mathrm{~m}$ from the base of the receiver mooring. Bottom depth varied from 195 to $588 \mathrm{~m}$. Transmitters were suspended 0.5 and $5 \mathrm{~m}$ off bottom, and receivers at 145-400 $\mathrm{m}$ below the sea surface depend on bottom depth. Receivers were deployed for 162-595 days; however, maximum transmission time was 365 days.
\end{abstract}

Results: The rate at which acoustic transmissions were detected by the receivers decreased with distance from the transmitters, mostly monotonically; at first gradually, from transmitters at distances of 400-800 m from the receivers, and then more steeply at distances beyond $800 \mathrm{~m}$. Considerable variability in detection rates was observed, including low detection rates from individual locations and distances. Temporal changes in detection rates were observed that included convergence/divergence between detection of transmitters at a given distance from receivers but that were suspended at different elevations above bottom; stepwise seasonal shifts in mean detection; diurnal periodicity that was likely due to diurnal winds; and tidally mediated detection cycles. We determined that a linear "gate" of receivers spaced $1000 \mathrm{~m}$ apart would have a very high probability $(\geq 0.99)$ under most conditions of detecting an acoustically tagged Pacific halibut transiting the gate, and that tagged-halibut identification rates using 2400-m receiver spacing could approach or exceed $90 \%$. However, during episodic periods of relatively poor tag detection, these rates are likely to decline to 60-80\%; and to below 10\% under extreme conditions.

Conclusions: Acoustic telemetry is a feasible technique for monitoring the movement of deepwater epibenthic fishes. However, temporal and spatial variability in detection rates, especially in seasonally stratified waters, has a strong potential to impart biases on study results and generate spurious patterns unrelated to tagged-fish behavior. The nature of such biases should be carefully considered during array placement and data interpretation. Range testing should be conducted at all geographic locations at which arrays are to be established, rather than extrapolating

\footnotetext{
*Correspondence: tim@iphc.int

${ }^{1}$ International Pacific Halibut Commission, 2320 W. Commodore Way,

Suite 300, Seattle, WA 98199-1287, USA

Full list of author information is available at the end of the article
} 
from a few test locations. Arrays should always contain sentinel tags to monitor detection rates and account for transient features that affect those rates. We also note the necessity of placing at least two gates at any given location in order to substantiate movement of tagged animals past any desired point of reference.

Keywords: Fish, Marine, Telemetry, Stationary acoustics, Detection range, Deepwater

\section{Background}

Extensive geographic movement is an influential element of the population dynamics of sablefish (Anoplopoma fimbria) and Pacific halibut (Hippoglossus stenolepis), two of the eastern Pacific's most commercially important groundfish species, and mark-recovery tagging data play a large role in the management structures employed for both species. Sablefish in US Federal waters are currently managed by US National Marine Fisheries Service (NMFS) as a single population [1] based largely on conventional tagging data and genetic evidence $[2,3]$ that suggest considerable mixing throughout offshore waters from the Aleutian Islands and eastern Bering Sea and southward to the Alaskan panhandle. In contrast, analyses of tagging data [1, 4] have indicated only limited exchange between this stock component and the state-managed waters of Southeastern Alaska [1], and so the latter is managed separately using closed-population mark-recapture-based abundance estimates [5]. For Pacific halibut, extensive mixing suggested by passive integrated transponder (PIT) tagging programs [6] has served to justify coastwide assessment modeling [7] and conventional tagging data have been used to estimate seasonal cross-boundary migration rates [8] that are important to consider when discussing fishery season dates (sensu [9]). However, conventional tag-return data can be biased by varying levels and loci of fishing (tag return) effort (sensu [10]), biased rates of tag detection (sensu [11]) or reporting (sensu [12]), and the rates at which tagged animals mix into the untagged population during the interval between mark and recapture (sensu [13]). Furthermore, mark-recovery methods that produce only endpoint data (i.e., locations at tagging and recapture) are unable to address many of the more complex elements of fish-movement dynamics, such as the timing, frequency, and recurrence of movements.

As an adjunct to conventional tagging programs, more detailed information regarding the migratory dynamics of fishes may be obtained using acoustic tagging, by "gating off" important movement routes with lines of acoustic receivers at likely points of fish ingress and egress [14, 15]. In contrast to conventional mark-single-recapture tagging (e.g., external tags or PIT tags, with recaptures occurring in commercial or recreational fisheries), acoustic telemetry enables multiple detections of individually tagged animals, often with high detection probability.
That said, sablefish often range to ocean depths of up to $700 \mathrm{~m}$ and have been recorded at over $2000 \mathrm{~m}$ depth [16]; Pacific halibut are commonly caught in the commercial fishery at up to $700 \mathrm{~m} \mathrm{[17]} \mathrm{and} \mathrm{have} \mathrm{been} \mathrm{shown} \mathrm{to}$ visit depths of at least $844 \mathrm{~m}$ during the winter spawning season [18]. The interplay of deep water, complex bathymetric and shoreline contours, high energy storms and sea state, large $(5+\mathrm{m})$ tidal ranges, strong currents $\left(3+\mathrm{m} \mathrm{s}^{-1}\right)$, high rainfall and attendant episodic infusion of fresh water, water stratification due to pycnoclines, and periodic heavy vessel traffic are among the factors that can affect the detection of signals from acoustically tagged fish (e.g., [19]) and introduce spatial and temporal biases that can complicate the interpretation of acoustic tag data. Thus, an initial step in the process of evaluating the effectiveness of acoustic telemetry in habitats such as those inhabited by these two species is to determine the range and performance of ultrasonic transmitters and receivers that are likely to be used, under the conditions that would typically be encountered during the course of deployments. Welsh et al. [20] emphasize the desirability of conducting range tests specific to individual studies, locales, and target species and Kessel et al. [21] have encouraged the use of fixed "sentinel tags" within all active acoustic arrays in order to monitor variance in tagdetection efficiency over time.

However, the existing literature describing dedicated acoustic range tests, gear performance, and acoustic positioning systems for tagged fish is largely lacking in deepwater (here, defined as depths $>200 \mathrm{~m}$ ) studies. Rather, the majority of empirical range-testing studies have been conducted at depths of $<50 \mathrm{~m}$ [e.g., 22-28], describing applications in which the relative depth of the acoustic receivers and their tagged targets would be quite similar. For deepwater benthic species, depth limitations associated with moored acoustic receivers can introduce considerable differences in depth between the receivers and tagged targets, increasing their relative distance from one another and resulting in a greater probability that acoustic interference might exist within the intervening water column. Furthermore, only one study [29] has provided detection-at-distance data for acoustic tags deployed in an Alaskan setting likely to be representative of our target array locations. Here, we conducted tests to determine the detection range of VEMCO Limited (Halifax, Canada) V16-5H acoustic transmitters using VR2W receivers 
in deep marine waters of Southeast Alaska. Our goal was to describe nominal tag-detection rates relative to their distance from receivers under optimal conditions, and to investigate and characterize temporal variance in tag detection and associate this variance with transient environmental conditions (e.g., surface noise, seasonal pycnoclines, tidal periodicity) that might induce it. These tests were necessary to help determine the effective receiver spacing for potential acoustic gates and arrays, and thus the cost associated with the possible implementation of acoustic telemetry programs for deepwater epibenthic fishes in this area. In addition, such information may be useful to the tagging community at large, as researchers increase acoustic-tagging studies of deepwater demersal and mesopelagic species such as lingcod (Ophiodon elongatus [22, 29]), rockfishes (Sebastes spp. [30]), and Greenland sharks (Somniosus microcephalus [31, 32]).

\section{Methods}

From August 2009 through May 2011, we conducted tests to determine the detection range between VEMCO V16-5H acoustic transmitter tags and VR2W omnidirectional acoustic receivers. The $\mathrm{V} 16-5 \mathrm{H}$ transmitters were chosen because they were one of the most powerful tags available, with attendant high detection range, and because average-sized sablefish and Pacific halibut can easily accommodate this tag. The transmitters transmitted at a frequency of $69 \mathrm{kHz}$, with a power output of $165 \mathrm{~dB}$ re $1 \mathrm{uPa}$ at $1 \mathrm{~m}$ distance from the tag. Signal transmission rate varied pseudo-randomly among transmitters with one tag ID (a.k.a., "code burst") every 170-310 s with a nominal (mean) delay time of $240 \mathrm{~s}$ between code bursts.

\section{Test array locations}

Tests were conducted in the marine waters of Southeast Alaska in depths ranging from 200 to $588 \mathrm{~m}$ at locations varying from a relatively narrow passage in interior waters to offshore locations on the continental shelf. Testing was conducted by deploying subsurface moorings at each of six locations (stations). Station locations were those likely to be instrumented to address movement questions related to residency patterns of sablefish and Pacific halibut occupying the waters of Chatham Strait (Fig. 1), and alongshore migration on the continental shelf of Southeast Alaska. The complement of moorings at each location included a receiver node with one or two acoustic receivers, and five transmitter nodes spaced linearly in $200-\mathrm{m}$ increments at distances ranging from 200 to $1200 \mathrm{~m}$ from their receiver node.

We conducted two cruises to deploy receivers and transmitters: the first from 23 to 26 August 2009; the second from 21 to 25 May 2010. During the first deployment cruise, four stations (Fig. 1) were established at three locations within protected inside waters: (1) two stations (Stns. 1 and 2) at the mouth of Chatham Strait; (2) one station in central Frederick Sound (Stn. 3); and (3) one station at the west end of Icy Strait, in South Passage (Stn. 4). Two offshore stations (Stns. 5 and 6) were established in 2010, located southwest of Cape Ommaney at the southern tip of Baranof Island.

\section{Array design}

At Stations 1-4, transmitter nodes were placed in lines at distances of 400, 600, 800, 1000 and $1200 \mathrm{~m}$ from the base of their receiver nodes (Table 1, Fig. 2). Data obtained from the Station- 4 receiver following its premature release and recovery in March 2010 (see below) suggested that maximum signal detection might occur from transmitters placed $<400 \mathrm{~m}$ from their receivers. Therefore, the 2010 deployments (Stns. 5 and 6) included transmitter nodes at $200 \mathrm{~m}$ from the base of these receiver moorings, but with no $1200-\mathrm{m}$ transmitter nodes.

Each transmitter node consisted of a tether constructed of $6 \mathrm{~m}$ of $8-\mathrm{mm}$ diameter ultra-high molecular weight polyethylene line (Dyneema; DSM, Heerland, the Netherlands) buoyed with a $23-\mathrm{cm}$ diameter, round, hard plastic trawl float, and anchored to a $280-\mathrm{kg}$ steel railroad-car wheel. Two $69 \mathrm{kHz}, \mathrm{V} 16-5 \mathrm{H}$ transmitters, programmed to transmit for 365 days, were attached to the tether. One transmitter was suspended at $0.5 \mathrm{~m}$ and the other at $5 \mathrm{~m}$ above the sea floor (hereafter, referred to as transmitter "elevation"; Fig. 2). The two transmitter elevations were chosen to mimic the distance from the benthos at which Pacific groundfish are typically observed: near-bottom $(0.5 \mathrm{~m})$ for benthic species such as flatfishes, lingcod, and skates (Raiidae); off-bottom $(5.0 \mathrm{~m})$ for epibenthic species such as sablefish, Pacific cod (Gadus macrocephalus), and rockfishes. Transmitters were attached along the tethers using nylon zip ties.

Receiver nodes at each station consisted of variablelength (200-588 m, depending on ocean depth) tethers of 8-mm Dyneema, buoyed with three 46-cm diameter hard plastic trawl floats, and anchored using a 280-kg steel railroad-car wheel (Fig. 2). The first $1 \mathrm{~m}$ of tether above each receiver anchor was composed of $9.5-\mathrm{mm}$ galvanized chain to prevent chafing. Either one (Stns. 3-6) or two (Stns. 1 and 2) receivers were attached to the tethers, above benthos (Teledyne Technologies, Falmouth, USA) 875-TD acoustic releases. At Stations 1 and 2, which were placed in water depths in excess of $400 \mathrm{~m}$, acoustic receivers were placed at each of two depths (150 and $400 \mathrm{~m}$ below the surface) in order to evaluate the effect of varying receiver depth on acoustic signal detection. At stations that were placed in water shallower than $400 \mathrm{~m}$ (Stns. 3-6), single receivers were used and positioned at $\sim 55-\mathrm{m}$ elevation above 


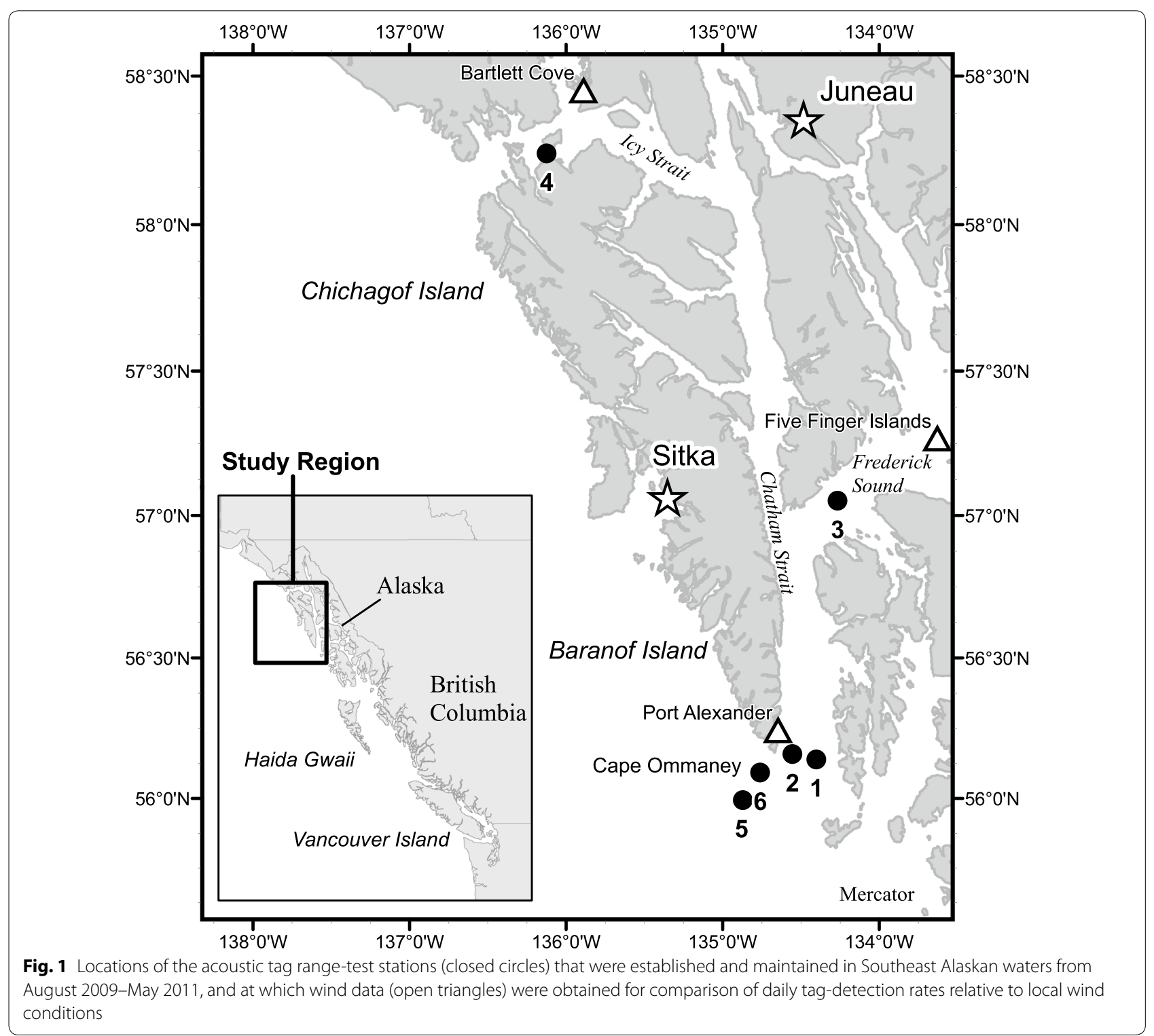

the sea floor (Table 1). At stations with single receivers, the acoustic releases were positioned $10 \mathrm{~m}$ below the receivers. For the double-receiver stations, the acoustic releases were positioned $10 \mathrm{~m}$ below the deeper (i.e., 400-m depth) receivers. Receivers were attached to their tethers using nylon zip ties, with the hydrophones pointed toward the ocean floor. The acoustic releases were to be activated at the end of the deployments in order to recover the receivers containing the signaldetection data.

\section{Acoustic node deployment}

Immediately prior to deploying nodes at each station, the speed and direction of the surface current was estimated by allowing the deployment vessel to drift for approximately $15 \mathrm{~min}$. This speed estimate, in combination with an estimate of the sinking rate of the railroadcar wheels and the known depth at each station, was used to determine the distance and direction up-current where each node was released, in order to maximize the likelihood of each node landing at its intended location.

In addition to the $\mathrm{V} 16-5 \mathrm{H}$ acoustic tags at each transmitter node, a single Lotek MA-16-332 76-KHz transmitter (Lotek Wireless, St. John's, Canada) was affixed to each transmitter and receiver node as an aid in pinpointing node locations after deployment, using the Lotek synthetic aperture positioning system (SYNAPS; [33]). We were concerned that upon release from the surface the nodes might drift off station because of the great water depth, potential for strong currents, and because the 


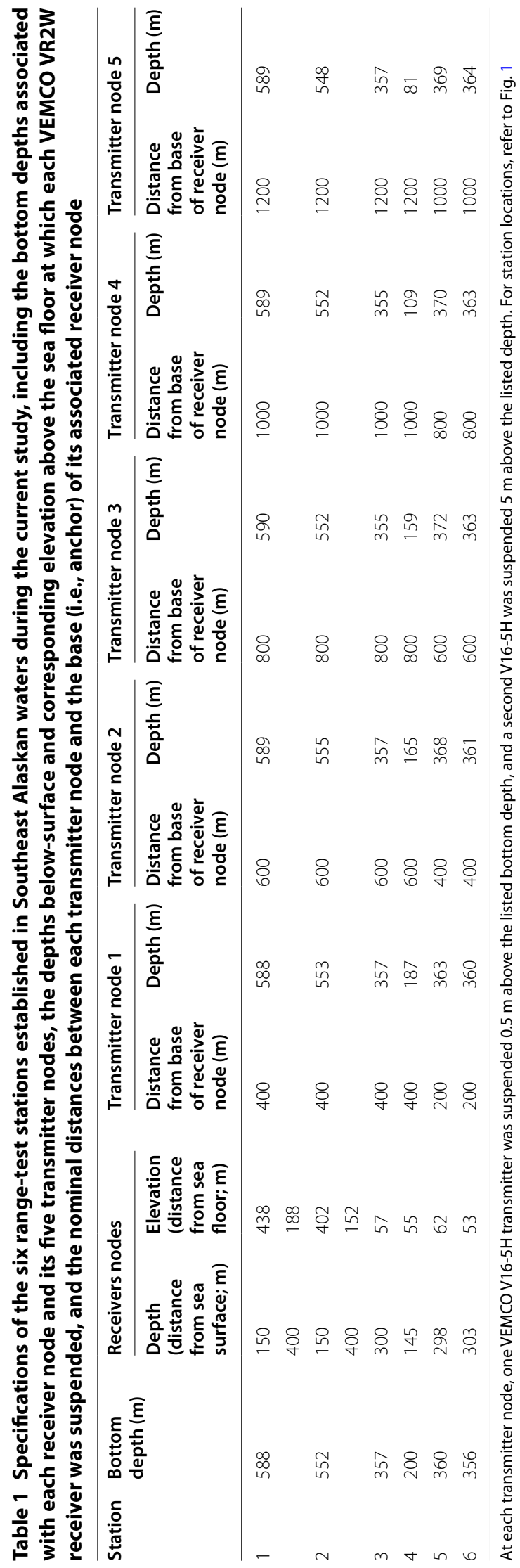




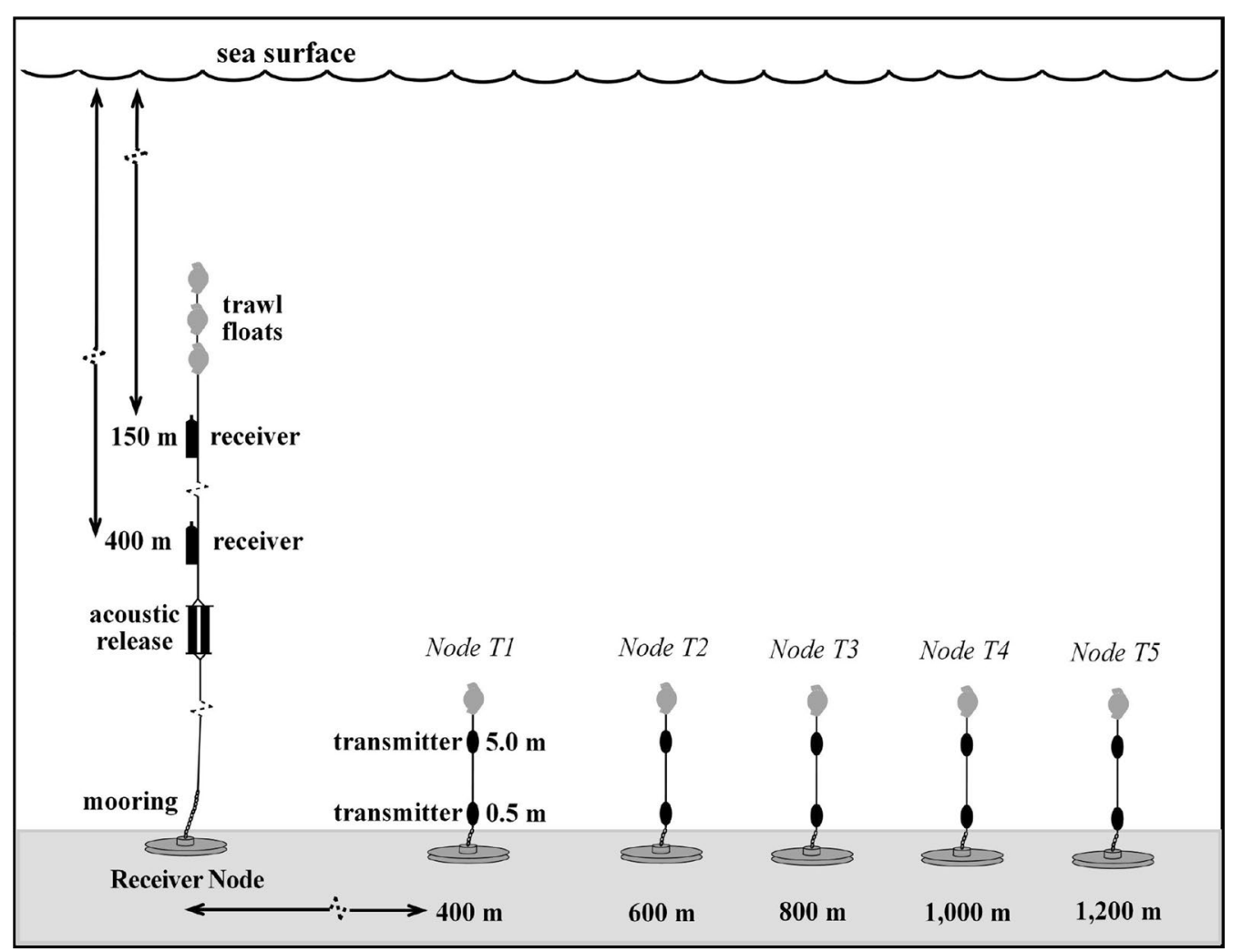

Fig. 2 Schematic of an acoustic tag range-test station showing the receiver node, with acoustic receivers suspended at two depths below the sea surface, and five transmitter nodes spaced from 400 to $1200 \mathrm{~m}$ from the base of the receiver node

broad surface area of the railroad-car wheels might cause them to plane sideways as the they descended.

\section{Data analyses: calculation of performance metrics}

Detection ranges were evaluated by calculating the following three performance metrics among transmitterreceiver combinations: (1) the detection-to-ping ratio; (2) the proportion of expected decoded transmitter signals, or tag IDs, that were detected over a given interval of time (a.k.a., "detection proportion"); and (3) a noise quotient [34]. Detection-to-ping ratio and noise quotient were not calculated for Station 4 because the data file needed for these calculations was lost.

Each ping that is produced by a transmitter is a single acoustic signal of specific frequency and duration that is followed by a specified period of silence. In order to produce a transmitter-specific identification code (transmitter ID), V16-5H transmitters emit a series of eight pings (i.e., a code burst) with temporal characteristics that are unique to that transmitter, in essence, an acoustic bar code. However, acoustic signals produced by sources other than VEMCO transmitters (e.g., surface noise, Alpheid snapping shrimp) may also be recorded by VR2W receivers, and potentially misidentified as transmitter pings. Thus, only uninterrupted code bursts that conform to stringent error-checking routines that verify their conformance to transmitter-ID specifications are identified by VR2W receivers as detections from specific transmitters. If every ping received by a transmitter ultimately results in the generation of coded detections, that receiver would generate one detection for every eight pings received. The receiver's detection-to-ping ratio can therefore be used as a qualitative measure of its ability to convert the pings that were recorded into decoded transmitter IDs (D. Webber, VEMCO Limited, Halifax, Canada; personal communication). This metric is simply calculated as: (number of detections $\times 8$ )/number of pings. Values approaching one indicate very high translation of pings into detections; values approaching 0 indicate that few pings could be interpreted by the receiver as transmitter signals.

Proportions of the expected transmitter detections that were ultimately resolved by each receiver over specified time periods, and for each transmitter-receiver combination, were then estimated as:

$$
P=\frac{D}{T \cdot d+\frac{\left(S_{\mathrm{dep}}+S_{\mathrm{ret}}\right)}{t}}
$$


where $P$ proportion of estimated expected detections resolved by the receiver, $D$ total number of detections by the receiver during the specified period, $T$ expected mean number of transmissions per day $=356, d$ total number of whole days during the specified period, $S_{\text {dep }}$ seconds between initial and final detection s on the first day of the period, $S_{\text {ret }}$ seconds between initial and final detection s on the last day of the period, $t$ nominal frequency of code bursts, in $\mathrm{s}=243$ (i.e., 1 code burst every $243 \mathrm{~s}$ ).

The denominator $t$ was derived by adding the 3 -s length of the ping train to the nominal delay between pings of $240 \mathrm{~s}$.

In addition to recording the total number of pings and fully decoded signal IDs that have been received, VR2Ws also record "synchronization intervals" (hereafter, "synchs"). Synchs represent the first identifiable element of each code burst and are used by the receiver to identify that a transmitter has begun broadcasting. Synchs are defined by the time that elapses between the first and second pings that are received within a code burst. If these two pings occur within the finely specified interval, the receiver interprets those signals as having initiated a valid code burst, records the synch, and then attempts to use the pings that follow to identify the transmitter code. Because the interval between the two pings is so precisely defined, the probability that acoustic noise could be spuriously interpreted as the beginning of a code burst is generally very small. Thus, the number synchs received is expected to provide an accurate record of the number of code bursts that were received. If, however, acoustic noise generates interference that occurs after the second ping, but before the code burst has ended, the receiver will be unable to derive a transmitter ID from that code burst. Using these data, a noise quotient can be calculated for any receiver and period of time that relates the number of code bursts that the receiver was able to identify to the total number of acoustic signals detected (individual pings; whether from tags or from other sources). Here, noise quotient was calculated following Simpfendorfer et al. [34] as: number of pings-(number of synchsnumber of pings necessary for ID), where number of pings necessary for ID $=8$.

\section{Statistical analyses}

Paired-sample $t$ tests were conducted to test for significant differences in the detection of acoustic signals emanating from near-bottom (i.e., 0.5-m elevation) versus off-bottom (i.e., $5.0-\mathrm{m}$ elevation) transmitters at each individual transmitter node, and in the detection of individual transmitters by shallow (i.e., $150-\mathrm{m}$ depth) versus deep (i.e., 400-m depth) acoustic receivers. These tests were conducted at two temporal scales (i.e., invoking considerably different sample sizes and, hence, degrees of freedom): (1) over the entire period during which each node pairing was deployed; (2) considering daily mean detection proportions (i.e., at a temporal resolution consistent with attempts to determine fish presence-absence at an acoustic array on a daily basis).

Relationships between daily total transmitter detections and regional daily mean wind conditions were investigated via simple linear regression. Daily mean wind speed data were obtained from the US National Climatic Data Center (https://www.ncdc.noaa.gov) for three locations near to our range-test stations (Fig. 1): Port Alexander (Stns. 1, 2, 5, and 6), Five Finger Island lighthouse (Stn. 3), and Bartlett Cove (Stn. 4). Wind speed data for Port Alexander were only available after 31 September 2009, and so the wind analyses for Station 2 omitted the first 38 full days (12.5\%) of that station's deployment; for all other stations daily wind data were available for full-study duration. For each analysis, observed daily mean wind speed (W) values were first converted to wind stress $(\mathcal{T})$, as a proxy for wave generation and its associated surface noise, following Brown et al. [35], as:

$$
\mathcal{T}=c \times W^{2}
$$

where $c$ (coefficient of mixing) $=0.0016$ for $W<7 \mathrm{~m}$ $\mathrm{s}^{-1}$; $=0.0025$ for $W>10 \mathrm{~m} \mathrm{~s}^{-1}$; scales linearly from 0.0016 to 0.0025 for $W$ from 7 to $10 \mathrm{~m} \mathrm{~s}^{-1}$.

Periodograms were computed using Fast Fourier transforms to investigate whether periodic cycles in tag detection occurred at range-test stations and identify and visualize the period lengths associated with any apparent periodicity. Prior to analyses, tag detections were pooled hourly among all transmitters at a given station that had been deployed at the same elevation (i.e., near-bottom and off-bottom). For the main analysis, periogram plots were generated by repeated estimation over 240 -h moving windows applied over the full course of each station's deployment. Analyses using larger time windows were also carried out to allow for the identification of periodicity occurring at lunar time scales (bi-monthly and monthly). Following calculation of the periodograms, two additional data transforms were conducted on the raw hourly data in order to confirm and investigate period lengths of specific interest. First, a smoothed time series was computed that captured diurnal periodicity (i.e., $24 \mathrm{~h}$ period length) and the result was subtracted from the raw data, allowing shorter-period residual cycle(s) to be visualized. Second, a highly smoothed time series was computed over the full period of deployment that allowed for longer-period cycles (i.e., over weeks-months) to be visualized. Both transformed datasets were plotted for 
comparison with the untransformed data, Fourier periodograms, and predicted semilunar tidal amplitudes for the study region.

All statistical analyses were conducted using the R statistical program version 3.3.2 [36]. Paired-sample tests and linear regressions were conducted following Radziwill [37]. Fourier transforms were conducted using the FFT function in the R package "stats." All errors reported herein represent one standard deviation about the reported mean values.

\section{Estimation of effective receiver spacing for a mobile target} As an aid in evaluating the utility of acoustic gates for addressing fish-movement questions, extreme-case, if not worst-case, scenarios may be developed to help estimate appropriate receiver spacing, and therefore the number of receivers needed to gate off fish-movement pathways. As an alternative to modeling detection as a continuous function dependent upon distance from the receiver, the detection radius for each receiver can be viewed as being composed of multiple, discrete, concentric rings of detection probabilities that decrease with increasing distance from the receiver (Fig. 3). Receivers positioned sufficiently close to one another in a linear array would form a series of intersecting rings of detection probabilities (Fig. 3). These rings would define a band of changing detection probabilities that constitute the acoustic gate, designed to detect acoustically tagged animals swimming through, or within the range of, the gate. At the outer edge their detection radii, the two circles that define each detection region would intersect at two points. Fish travelling along the line that connects these points (i.e., the common chord for the intersecting circles) would remain within the detection band for the shortest period of time at any constant movement speed, relative to any other path that may be travelled; travelling this path would therefore minimize the animal's probability of detection. As such, this length (hereafter, the "minimum intersection line," MIL) represents the most conservative estimate of the width of the acoustic gate. Increased receiver spacing would reduce this length, thereby reducing the gate's minimum detection probability, defined as the probability that at least one tag transmission will be received from a tagged fish as it passes through the gate. Halibut can be used for example calculations of such detection probabilities given observed tag-detection rates from range-test data.

Here, we calculated the length of the MIL associated with paired receiver nodes as a function of receiver spacing, assuming that the detection radii for both receivers is equivalent, as:

$$
\text { MIL }=2 \times \operatorname{sqrt}\left\{r^{2}-(0.5 d)^{2}\right\}
$$

where $r$ detection radius of the receivers; $d$ distance between the receivers.

This was then converted to an estimate of the minimum amount of time that would be required for an acoustically tagged Pacific halibut to travel through the gate, by dividing MIL by the halibut's cruising speed. Average cruising

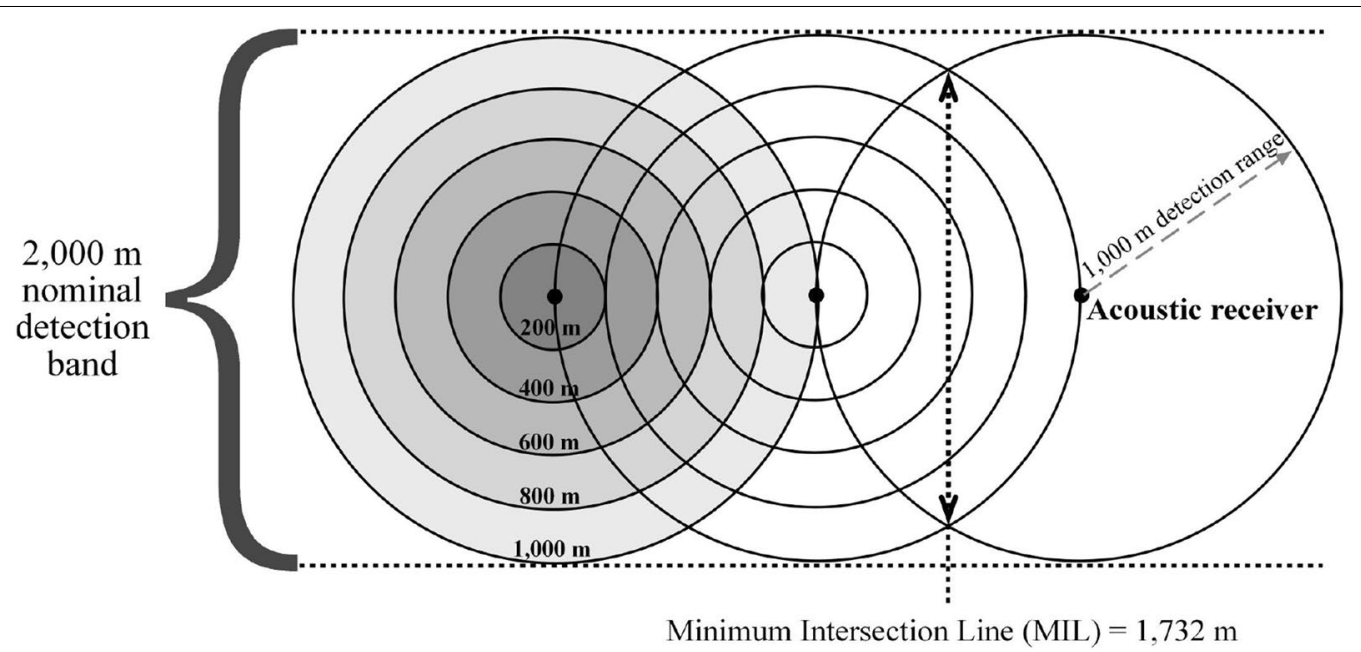

Fig. 3 Conceptual representation of the detection band for three acoustic receivers, each with a 1000-m effective tag-detection range, positioned in a linear array so as to form an "acoustic gate."The series of concentric rings around the receivers represent bands that are $200 \mathrm{~m}$ wide, with shading around the leftmost receiver representing tag-detection probabilities that decrease with distance from the central receiver. Detection rings around the rightmost receiver have been omitted for clarity. The shortest possible pathway through the gate is indicated by the vertical dashed line (i.e., from arrowhead-to-arrowhead): the "Minimum Intersection Line," which for a gate with a nominal bandwidth of $2000 \mathrm{~m}$ would be $1732 \mathrm{~m}$ in length 
speed for adult halibut has been observed in a laboratory setting to be approximately 0.5 body lengths per second (T. Loher, unpublished data). The total number of pings that are expected to be emitted by the fish's tag during its transit was then calculated as transit time (in s) divided by mean transmission frequency (=243 s; see above). The probability of at least one code burst being detected (hereafter, the probability of "identifying" the tagged ani$\mathrm{mal}$ ) is then:

$$
P=1-\left(1-p_{\mathrm{d}}\right)^{n}
$$

where $p_{\mathrm{d}}$ minimum detection proportion between tag and receiver; $n$ number of code bursts during transit of the MIL.

\section{Results}

\section{Array placement}

In only one case (Stn. 3) were we able to use Lotek ${ }^{\circledR}$ SYNAPS [33] to pinpoint the locations of the receivers and their transmitter nodes, due to the poor quality, inconsistency, and low number of detection s from the Lotek transmitters at all other stations. The reason(s) for the general lack of signal detection remains unknown. At Station 3 we obtained detections of sufficient quantity and quality to provide SYNAPS-estimated locations of the receiver node and its five transmitters, with modest precision. The estimated location of the receiver node was $10 \mathrm{~m}$ from its target location, and transmitter nodes 1-5 differed from their target locations by $20,31,80,71$, and $36 \mathrm{~m}$, respectively. At Stations 1-3 we were able to confirm that the receiver nodes were very close to their target locations based on the detection of their trawl floats on the vessel's depth sounder. The floats presented strong sonar returns at the target locations and depths for each station.

\section{Acoustic receiver recovery}

At the end of January 2010, the receiver node from Icy Strait (Stn. 4) was set adrift prematurely due to an acoustic release malfunction. This receiver drifted westward into the northern Gulf of Alaska and was recovered by a fisherman in March 2010, near Prince William Sound.

In May 2010, we attempted to recover receivers from Stations 1-3 but experienced complete failure of their acoustic release systems. The failures were presumably due to the side-by-side pairing of the releases, as recommended by the manufacturer to putatively increase the chance of recovering receivers should one of the releases fail. This configuration was later demonstrated to cause binding in the attachment chain, leading to inability for the chain to slide off the release arms in the presence of upward buoyant force. In June 2010, we were able to recover the receivers from Station 2 after $12 \mathrm{~h}$ of dragging with a grappling hook. In May 2011, the receiver at Station 3 was retrieved in a similar manner. The receivers from Station 1 were not recovered, although the node's presence was confirmed by the appearance on the vessel's depth sounder of the trawl floats, suspended at $127 \mathrm{~m}$.

Due to the malfunctions experienced at Stations 1-3, single acoustic releases were used at Stations 5 and 6, deployed thereafter. In May 2011 these receivers were retrieved via normal activation of their acoustic releases. Receiver nodes that were successfully recovered had been deployed for periods ranging from 160 to 621 days; however, the transmitters were programmed to cease transmitting after 365 days.

\section{Detection rates}

Excluding each receiver's day of deployment and day of retrieval (i.e., days with only partial data), daily detectionto-ping ratios varied from a low of $55 \%$ at the shallow receiver of Station 2 on 24 June 2010, to a high of $86 \%$ at Station 5 on 30 October 2010. Receiver-specific daily detection-to-ping ratios averaged over the entire course of deployment were fairly consistent and ranged from a low of $73 \pm 4.6 \%$ (shallow receiver at Stn. 2) to a high of $79 \pm 4.6 \%$ (Stn. 5 ).

Over the full course of deployment, proportions of the absolute estimated number of transmission IDs that were successfully detected (hereafter, "detection proportions") among transmitter-receiver combinations varied from 0.04 to 0.84 (Fig. 4). Among the five stations, detection rates most commonly decreased monotonically with increasing distance between the transmitters and their receivers, at distances $>400 \mathrm{~m}$ (Fig. 4). However, there were a number of differences among stations. At Station 2 (Fig. 4a, b), the proportion of detections from the $0.5-\mathrm{m}$-elevation transmitter at both receiver depths were less at 800-m distance than from the 1000-m node. That this pattern was observed only from the near-bottom transmitter suggests that a physical obstruction may have been between this transmitter and the station's receivers. The transmitter node may have settled in a depression or next to an object (e.g., a rocky outcrop or kelp) of sufficient size to have blocked some of its transmissions. At the stations on the continental shelf (Stns. 5 and 6), with transmitter nodes closest $(200 \mathrm{~m})$ to their receivers, consistently lower detection rates were observed from the 200-m transmitters than from those at $400 \mathrm{~m}$ (Fig. 4e, f), for both transmitter elevations.

Mean detection proportion for all 5-m-elevation transmitters pooled over the full period of deployment of those transmitters $(M=0.63 \pm 0.205)$ was significantly greater (paired-sample $t$ test, $t(28)=2.059, p=0.049$ ) than for transmitters suspended at $0.5 \mathrm{~m}(M=0.60 \pm 0.224)$. At Station 2, where two receiver depths were tested, 

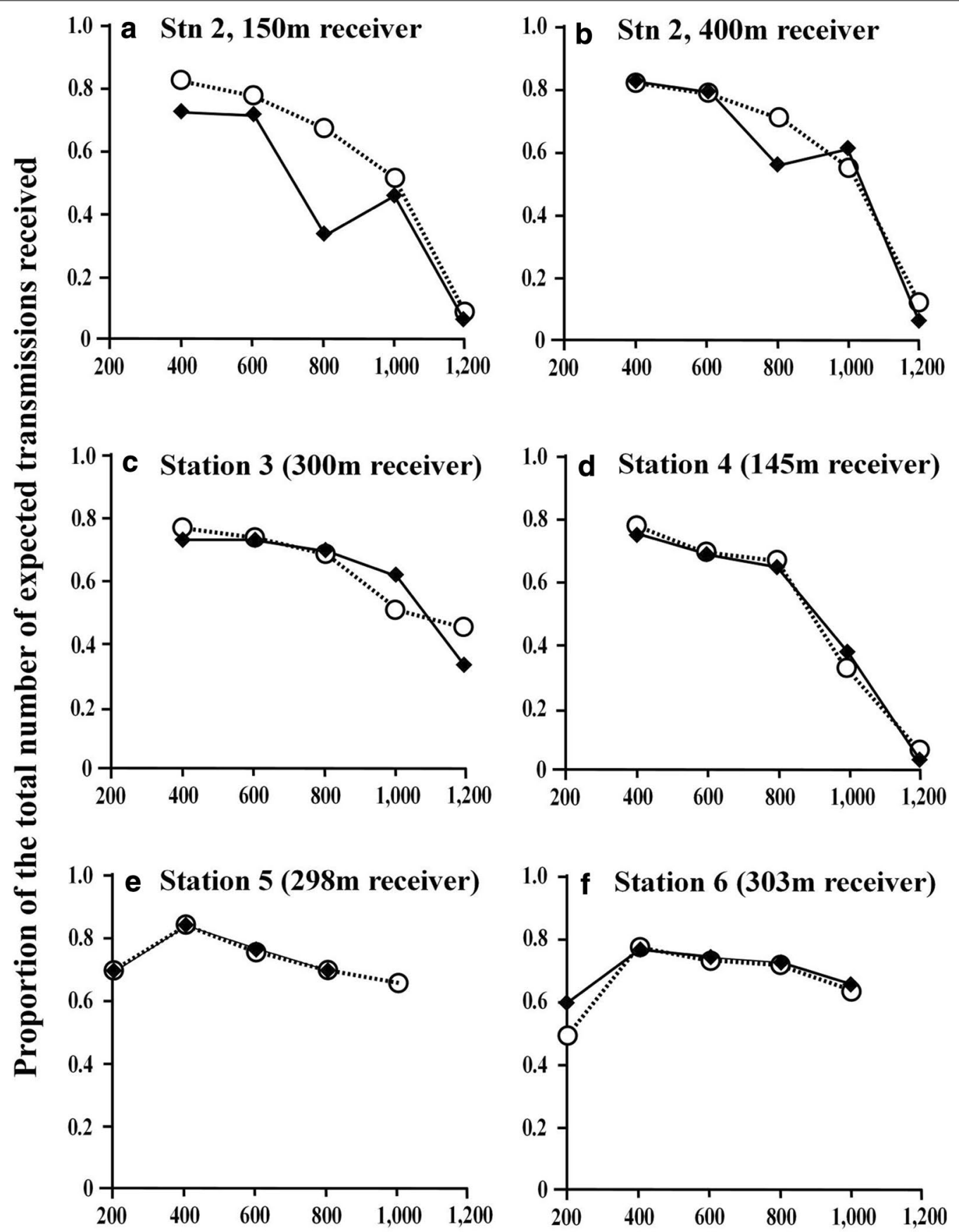

\section{Distance between receiver and transmitter moorings $(\mathrm{m})$}

Fig. 4 Relative to the total number of tag ID transmissions estimated to have occurred for each acoustic transmitter, the proportions that were detected by each of the acoustic receivers that were placed at range-test Stations 2-6. a Receiver placed at $150 \mathrm{~m}$ depth at Station 2; $\mathbf{b}$ receiver placed at $400 \mathrm{~m}$ depth at Station 2; c receiver placed at $300 \mathrm{~m}$ depth at Station 3; d receiver placed at $145 \mathrm{~m}$ depth at Station 4; e receiver placed at $298 \mathrm{~m}$ depth at Station 5; and $\mathbf{f}$ receiver placed at $303 \mathrm{~m}$ depth at Station 6. In each panel, the receiver's depth below the sea surface is indicated. Open circles connected by dashed lines indicate transmitters that were suspended $0.5 \mathrm{~m}$ off bottom and solid diamonds connected by solid lines represent transmitters suspended $5.0 \mathrm{~m}$ off bottom 
full-period detection proportions at the deeper receiver $(0.58 \pm 0.272)$ were significantly greater (paired-sample $t$ tests, $t(4)=3.072, p=0.037)$ than at the shallower receiver $(0.48 \pm 0.274)$.

\section{Daily detection proportions: effects of distance between receivers and transmitters}

Reflective of the total numbers of detections, daily detection proportions (Figs. 5, 6, 7) generally declined monotonically with increasing distances between transmitters and receivers (e.g., Fig. 6e-h). As with total detections, exceptions were evident at Stations 5 and 6 (Fig. 7), which showed increases in detection rate as transmitter-node distances increased from 200 to $400 \mathrm{~m}$, before declining at distances beyond $400 \mathrm{~m}$. Also, detection proportions declined between 600 and $800 \mathrm{~m}$ at Station 2 for both receivers and then increased at $1000 \mathrm{~m}$ before declining to their lowest levels at $1200 \mathrm{~m}$. The largest incremental decrease in transmitter detection was most often observed between 1000 and $1200 \mathrm{~m}$ (Fig. 4).

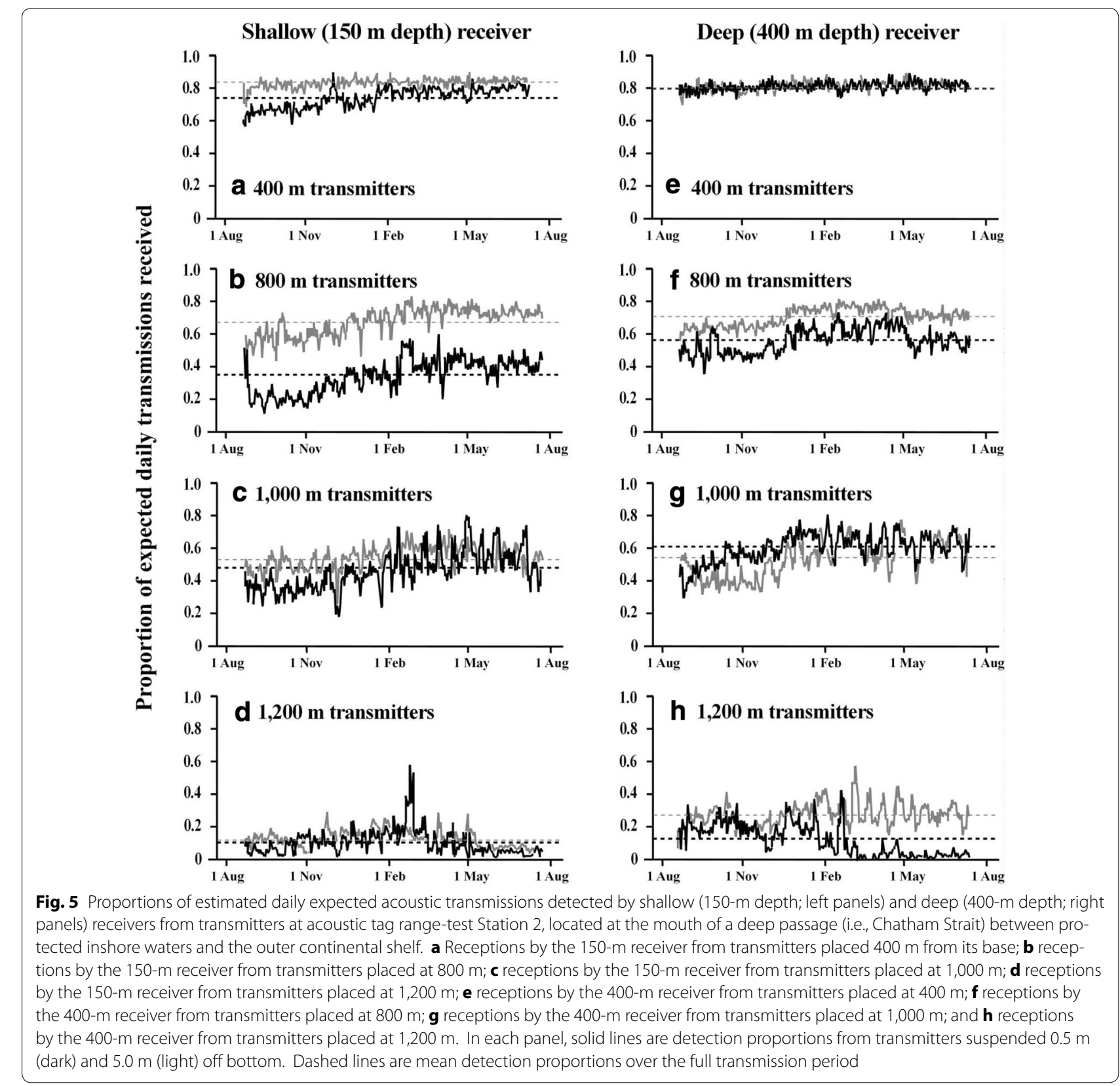



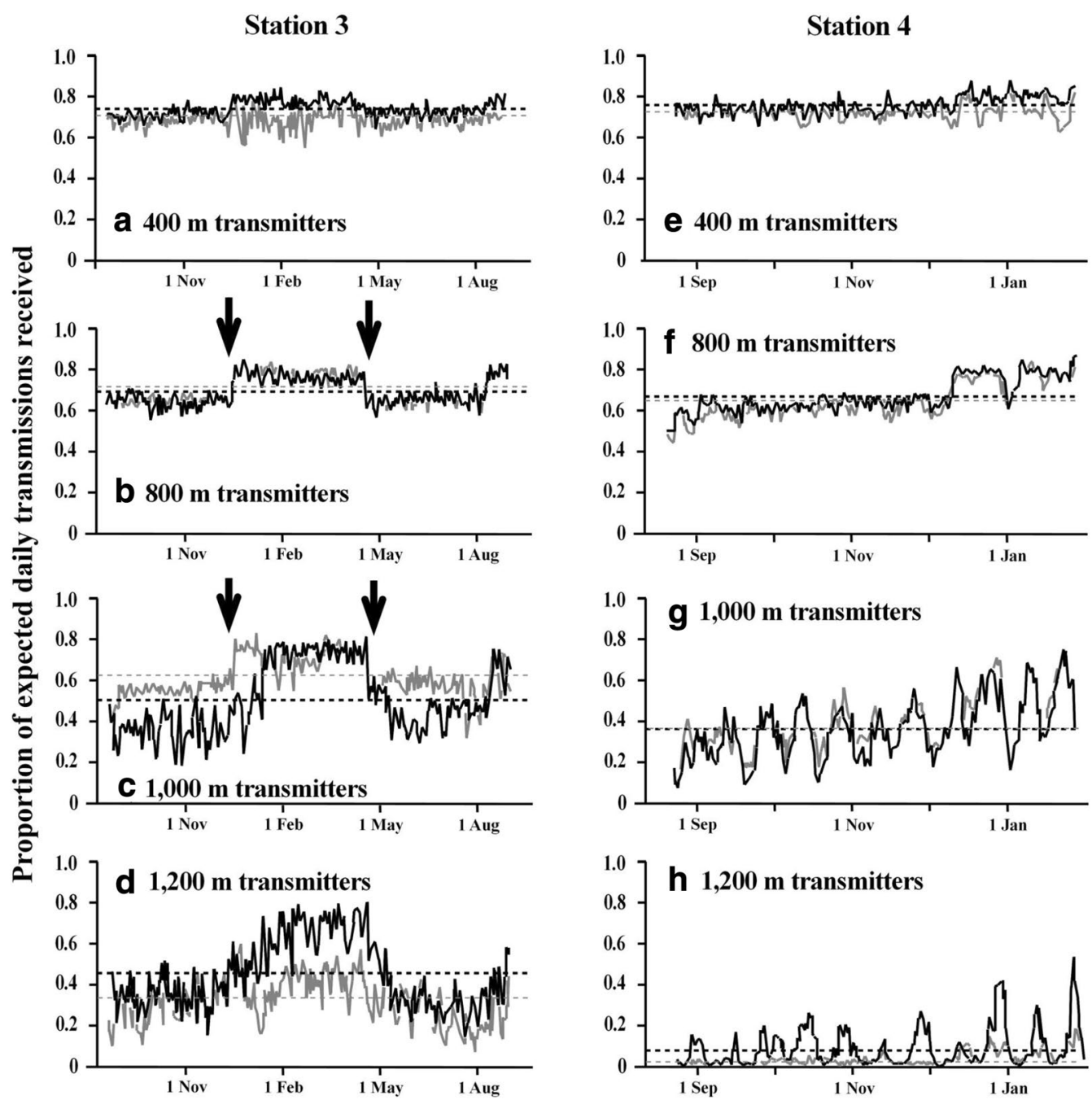

Fig. 6 Proportions of estimated daily expected transmissions detected at acoustic tag range-test Station 3 (located in a broad sound within protected coastal waters; left panels) and at Station 4 (within a narrow inshore passage; right panels). a Receptions at Station 3 from transmitters placed at $400 \mathrm{~m}$ from the base of the receiver; $\mathbf{b}$ receptions at Station 3 from transmitters placed at $800 \mathrm{~m}$; c receptions at Station 3 from transmitters placed at 1,000 m; d receptions at Station 3 from transmitters placed at 1,200 m; e receptions at Station 4 from transmitters placed at $400 \mathrm{~m} ; \mathbf{f}$ receptions at Station 4 from transmitters placed at $800 \mathrm{~m} ; \mathbf{g}$ receptions at Station 4 from transmitters placed at 1,000 $\mathrm{m}$; and $\mathbf{h}$ receptions at Station 4 from transmitters placed at 1,200 m. In each panel, solid lines are detection proportions from transmitters suspended $0.5 \mathrm{~m}$ (dark) and $5.0 \mathrm{~m}$ (light) off bottom; dashed lines are mean detection proportions over the full transmission period

\section{Daily detection proportions: effects of transmitter elevation and receiver depth}

Pooled among stations and transmitter-receiver distances over the course of the deployments, a significantly greater overall mean daily detection proportion (paired-sample $t$ test, $t(8704)=25.138, p<0.001)$ was observed for the 5-m-elevation transmitters $(M=0.63 \pm 0.205)$ than for transmitters suspended at $0.5 \mathrm{~m}(M=0.60 \pm 0.224)$. However, the magnitude of this difference was small (i.e., $~ 3 \%$ increase in mean detection rate) relative to the broad range of detection proportions that were observed. Furthermore, the logistical relevance of this mean difference is questionable given the occurrence of striking temporal patterns in detection rates, when considering specific transmitter-receiver distances, which at times demonstrated long periods during which detection was markedly greater for the near-bottom transmitters (e.g., Figs. 5g, 6d). Important temporal trends in relative detection rate took four basic forms: (1) decreased detection proportion for one transmitter elevation relative to the other, but with detection from both elevations covarying throughout deployment (Fig. 5b, c, f); (2) initial difference between the transmitter elevations followed by convergence (Fig. 5a, g); (3) initial similarity followed by 
Station 5

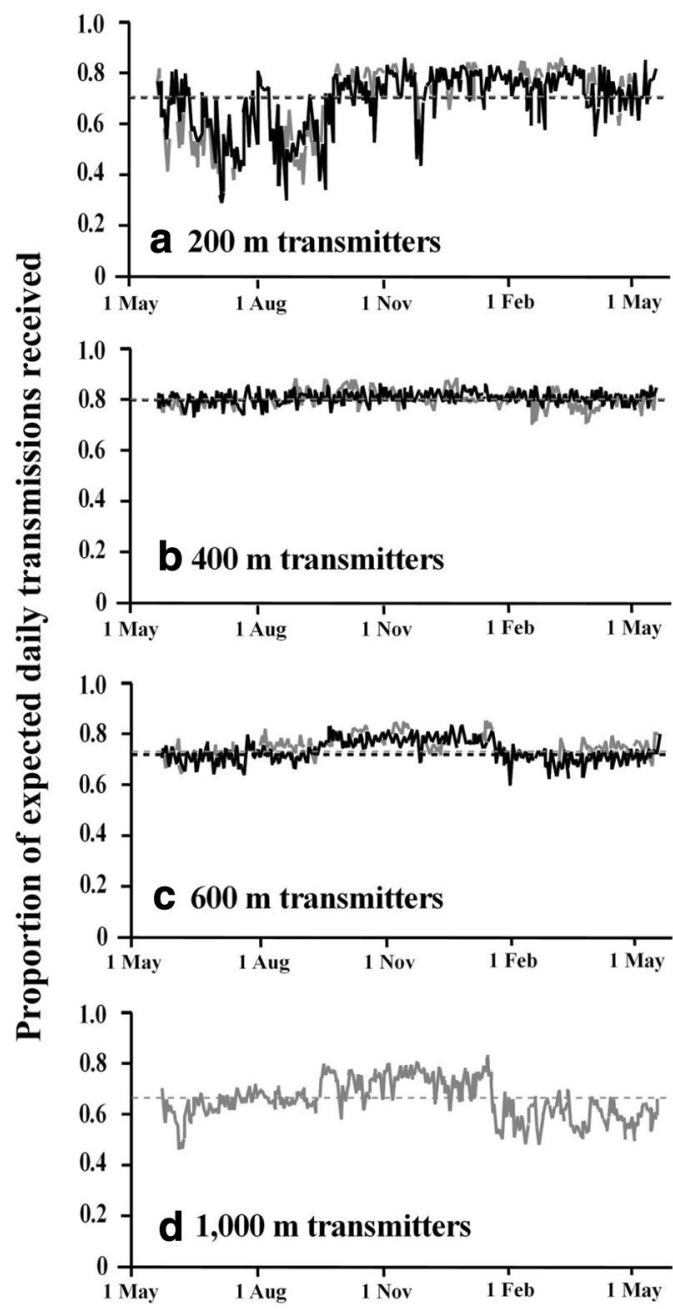

Station 6
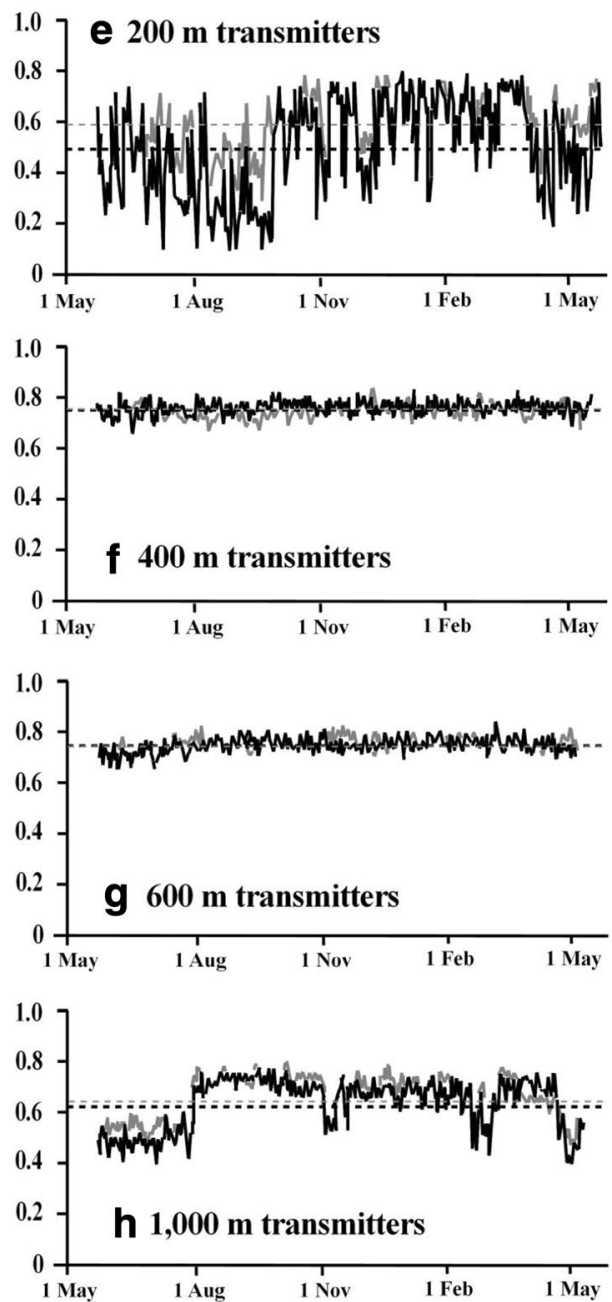

Fig. 7 Proportions of estimated daily expected transmissions detected at acoustic tag range-test Stations 5 (left panels) and 6 (right panels), both located in open coastal continental shelf habitat. a Receptions at Station 5 from transmitters placed $200 \mathrm{~m}$ from the base of the receiver; $\mathbf{b}$ receptions at Station 5 from transmitters placed at $400 \mathrm{~m}$; c receptions at Station 5 from transmitters placed at 600 m; d receptions at Station 5 from transmitters placed at 1,000 m; e receptions at Station 6 from transmitters placed at $200 \mathrm{~m}$; $\mathbf{f}$ receptions at Station 6 from transmitters placed at $400 \mathrm{~m} ; \mathbf{g}$ receptions at Station 6 from transmitters placed at $600 \mathrm{~m}$; and $\mathbf{h}$ receptions at Station 6 from transmitters placed at 1,000 $\mathrm{m}$. In each panel, solid lines are detection proportions from transmitters suspended $0.5 \mathrm{~m}$ (dark) and $5.0 \mathrm{~m}$ (light) off bottom; dashed lines are mean detection proportions over the full transmission period

divergence (Fig. 5h); and (4) periodic convergence/divergence (Fig. 6c, d).

At Station 2, where two receiver depths were tested, daily detection proportions (Fig. 5) were significantly greater at the deeper receiver than at the shallower receiver for all $0.5-\mathrm{m}$-elevation transmitters (pairedsample $t$ tests, $t(303)$ ranging from 6.622 to 44.954 , all $p<0.001$ ). For the transmitters suspended at 5-m elevation, significantly greater detection occurred at the deeper receiver for transmitter nodes located at 800 $1200 \mathrm{~m}$ (paired-sample $t$ tests, $t(303)$ ranging from 4.117 to 36.083 , all $p<0.001$ ), but not for the transmitters located closer to the receivers. At the $600 \mathrm{~m}$ transmitterreceiver distance, no difference was observed between the shallow and deep receivers (paired-sample $t$ test, $t(303)=0.576, p=0.565)$, while significantly greater detection of the 400-m transmitters occurred at the shallow receiver (paired-sample $t$ test, $t(303)=8.661$, $p<0.001$ ).

\section{Daily detection proportions: temporal trends}

Notable temporal patterns in moored transmitter detection, the nature of which could potentially bias the interpretation of data from tagged animals, included: (1) 
smoothly trended changes in detection over time; (2) highly variable detection rates; and (3) abrupt, stepwise shifts in transmitter detection. Although most transmitter-receiver combinations displayed either trended or stepwise changes over their deployment periods, in a few cases relatively large variability was observed throughout. Such high variability was particularly pronounced for the 200-m transmitters at Station 5, beginning at deployment and extending to mid-September 2010 (Fig. 7a). This variability decreased afterward, but was still approximately twice that observed from the 400-m transmitters (Fig. 7a vs. b). A similar pattern was observed from the 200-m transmitters at Station 6, but day-to-day variability was even greater than at Station 5 and persisted throughout deployment (Fig. 7e).

Apparent seasonal shifts in detection were observed at many stations. These were most pronounced at distances beyond $400 \mathrm{~m}$ (e.g., Figs. 6a vs. b-d, 7b vs. c, d). Periods of greater transmitter detection began as early as August (Fig. 7h) and as late as mid-December (Fig. 6b, c), and ended between January and mid-May.

\section{Noise quotients}

Among all transmitter-receiver combinations, the daily mean time between detections varied from $257 \pm 133.3 \mathrm{~s}$ (for the 5-m-elevation transmitter at 400-m distance at Stn. 2) to $6138 \pm 11,964.9 \mathrm{~s}$ (the 5-m-elevation transmitter at 1200-m distance at Stn. 4). Of the 59 transmitterreceiver combinations, 31 displayed mean times between detections that were greater than the $310 \mathrm{~s}$ that represented the maximum-programmed interval between the transmissions of each transmitter. This is an indirect indication that factors (i.e., acoustic noise) other than the randomly programmed ping rate (i.e., ranging from 170 to $310 \mathrm{~s}$ ) affected time between detections. Daily noise quotients varied between a minimum of $-13,373$ at Station 6 to maximum of -33 at Station 3. Mean daily noise quotients ranged from $-6081 \pm 2500$ for Station 6 to $-2735 \pm 356$ for the shallow receiver at Station 2.

\section{Daily mean wind influence}

Regressions of total number of daily detection versus daily mean wind stress yielded coefficients of determination $\left(R^{2}\right)$ that ranged from near-zero to 0.11 . Although about half of the regressions $(47 \%)$ were significant $(p<0.05)$, the universally low $R^{2}$ values suggest that short-period mean wind conditions had little measurable influence on acoustic detections. Additionally, the signs of the regression coefficients were not consistent and statistically significant relationships were distributed between positive and negative slopes. Approximately $36 \%$ of the significant analyses suggested reduced detection with increasing wind speed, as might be expected (in particular, at Stns. 5 and 6), whereas in $64 \%$ of significant cases the relationships between wind speed and daily acoustic detections were positive (i.e., Stns. 3 and 4).

\section{Periodicity in tag detections}

The periodograms identified clear periodic cycles in tag detection that ranged from approximately $6-24 \mathrm{~h}$ (Fig. 8). No periodicity at period lengths $>24 \mathrm{~h}$ were apparent from these analyses. Among the detected periods, the
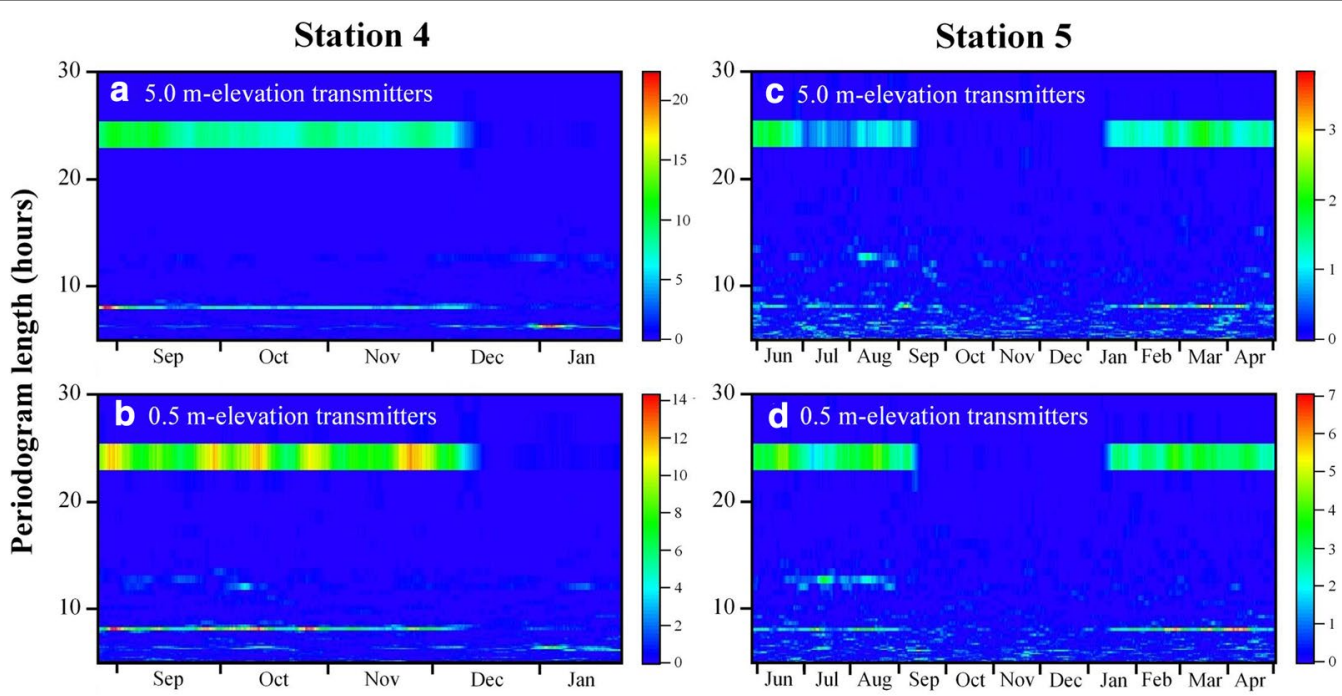

Fig. 8 Periodograms computed via Fast Fourier transform of hourly total acoustic transmitter detections at an acoustic range-testing station located within a narrow inshore passage (Station 4; left panels) and at a station on the exposed continental shelf (Station 5; right panels). a Receptions from transmitters suspended $5.0 \mathrm{~m}$ off bottom at Station 4; b receptions from transmitters suspended $0.5 \mathrm{~m}$ off bottom at Station 4; $\mathbf{c}$ receptions from transmitters suspended $5.0 \mathrm{~m}$ off bottom at Station 5; and $\mathbf{d}$ receptions from transmitters suspended $0.5 \mathrm{~m}$ off bottom at Station 5. Periodic cycles in tag detection are apparent at period lengths of $24,12.6,8$, and $\sim 6$ hours; note that the cycles with diurnal (24-hour) and 8-hr periodicity ceased during mid-winter 
diurnal (24-h) signal was most pronounced. Diurnal periodicity was apparent in both protected inshore waters and on the continental shelf (Fig. 8). It was more strongly observed in the inshore waters of Station 4 (Fig. 8a, b) and more weakly so at offshore Station 5 (Fig. 8c, d). Similar to the observation of stepwise seasonal changes in total tag detections at some stations (e.g., Fig. 6b, c), diurnal periodicity in tag detections was apparent during the relatively low-detection summer months, ceased in autumn, and then resumed in late-winter and spring. A signature that was similar to the diurnal pattern was also displayed with an 8-h period: this shorter-period cycle was apparent during summer and spring but absent during mid-winter. Weaker and relatively transient periodicity was observed at timescales consistent with the ebb-flood tidal cycle: at $12.6 \mathrm{~h}$ (Fig. 8b, d) and $\sim 6 \mathrm{~h}$ (Fig. 8a, b). Unlike the diurnal and 8-h cycles, some evidence of tidal detection cycles was observed throughout the year; in particular, in the 6-h cycle at Station 4 that extended into December and January after the diurnal signal had ceased (Fig. 8a, b).

The diurnal pattern in tag detection that was identified by periodogram was easily visualized in plots of the raw pooled data, especially at Station 4 (Fig. 9a). Closer inspection indicated that the diurnal detection cycle represented declining detection rates over the course of daylight hours followed by return to relatively high detection by morning. Removing the diurnal periodicity from the data confirmed the occurrence of the 8-h cycle (Fig. 9b), which appeared to primarily represent consistently low
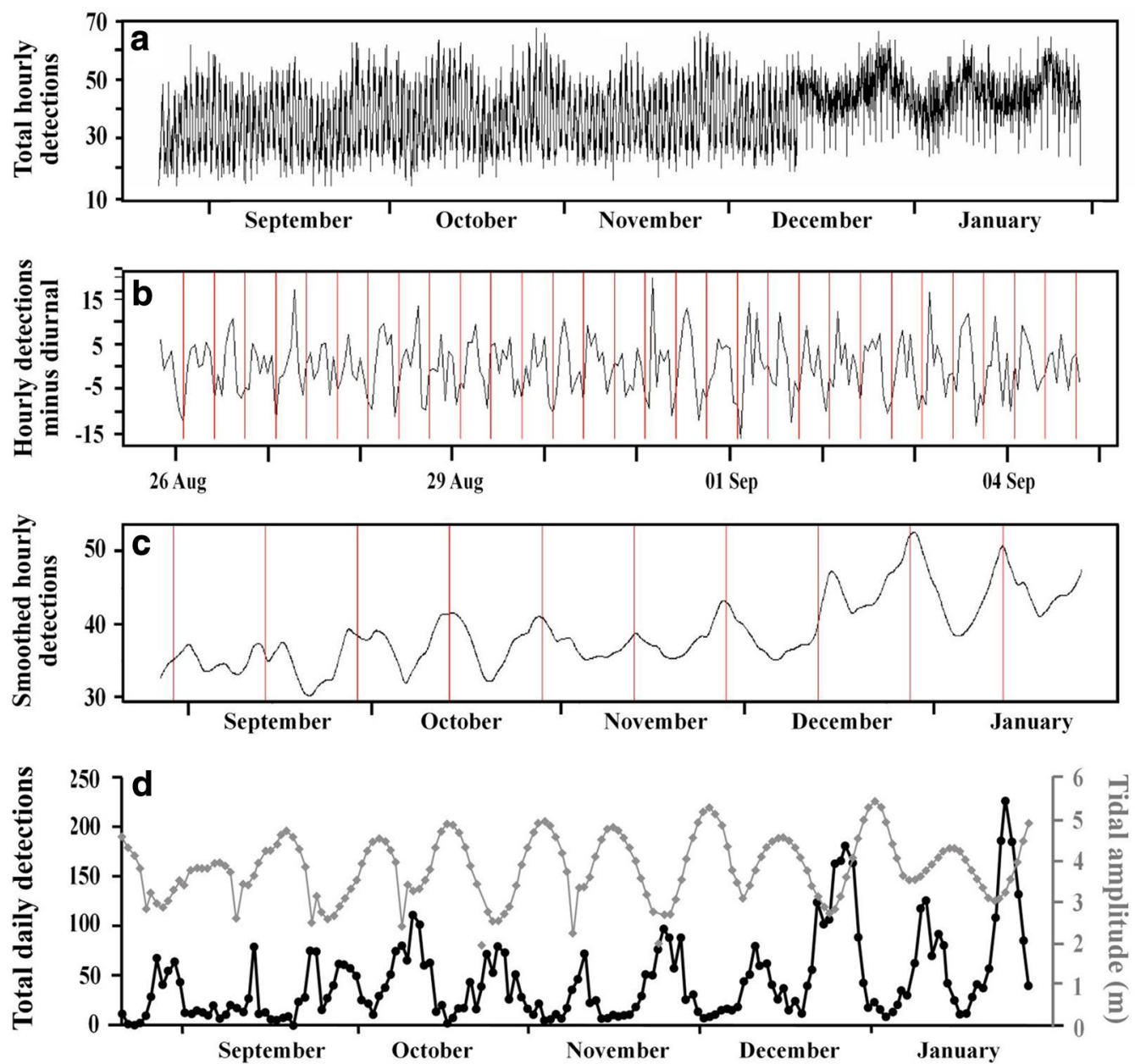

Fig. 9 Hourly acoustic transmitter detections from all transmitter nodes at acoustic tag range-test Station 4, located within a narrow inshore passage. The data are plotted in raw form over the full deployment period (a); for a selected 10-day period following subtraction of the diurnal cycle (b); and over the full deployment period after being smoothed (c). In b, the red vertical lines indicate 8-h periods; in c, they indicate 15-day periods. In d, total daily transmitter detections from the most distant transmitter node $(1200 \mathrm{~m})$ are plotted in relation to predicted semilunar tidal amplitude at the study site 
detection every $8 \mathrm{~h}$ followed by variably higher reception in subsequent hourly bins. A longer-period (roughly bi-monthly) trend in detection that seemed apparent in the raw hourly data (Fig. 9a) was more apparent after smoothing and corresponded to an approximately 15-day cycle. This period length was not detected via periodogram, but appeared to be driven by striking declines in signal reception, especially from the 1000- and 1200-m transmitters, that were in-phase with estimated tidal amplitudes (Fig. 9d).

\section{Effective receiver spacing for a mobile target}

Assuming that an adult Pacific halibut cruises at 0.5 body lengths $\mathrm{s}^{-1}$ (T. Loher, unpublished data), a 100-cm halibut (i.e., typical size for a halibut that has become fully selected to the commercial fishery) would cruise at approximately $0.5 \mathrm{~m} \mathrm{~s}^{-1}$. If receivers are spaced $1000 \mathrm{~m}$ apart, then at $1000 \mathrm{~m}$ from the receivers the intersecting outer margins of the detection rings of adjacent receivers will form a line that is $1732 \mathrm{~m}$ in length (Fig. 3). At constant cruising speed this halibut would swim this distance in $\sim 3464 \mathrm{~s}$. For V16-5H transmitters, we can assume that while the instrumented halibut transits this distance its tag's code bursts would be delayed by no more than $310 \mathrm{~s}$, which would result in at least 10 transmissions while within the detection band. In the current study, the lowest long-term average tag-detection proportion that we observed at $1000 \mathrm{~m}$ was 0.35 ; i.e., from the 0.5-m-elevation transmitter at Station 4 (Figs. 4, 6). If we assume this detection proportion throughout transit, the probability of at least one tag identification occurring at one receiver, from 10 code bursts, would be: 1$(1-0.35)^{10}=0.986$. However, because the halibut is swimming between two receivers, the probability that the fish's transit would produce at least one tag identification at either receiver between which the halibut has swum would be: $1-(1-0.35)^{20}=0.999$.

Alternatively, a range of worst-case scenarios may be calculated based on observations of short-period declines in detection probability. Cyclic variation in transmitter detection proportions indicates that conditions commonly occur that could markedly reduce a fish's probability of detection during transit. For the transmitters located at the 1000 m node at Station 4, troughs in daily detection proportion were observed at rough 2 -week intervals throughout the autumn and displayed values of $0.08-0.10$ (Fig. 6g). Resolved at hourly scales (i.e., the approximate total transit time that was suggested in the previous calculations) during reduced-detection periods, transmitter detection proportions pooled between elevations were sometimes as low as 0.04 . Considering a range of hourly-to-daily detection proportions of 0.040.10 , calculations equivalent to those reported above yield probabilities of tagged-fish identification ranging from 0.557 to 0.878 . These probabilities might be further reduced if periods of reduced transmitter detection are associated with periods of increased current speeds, during which an instrumented fish that swims with the current would be expected to transit the gate at increased speed. In extreme cases, tidally induced current speeds in South Passage (i.e., at Station 4) may reach $3 \mathrm{~m} \mathrm{~s}^{-1}$; adding this to the Pacific halibut's hypothetical transit speed would reduce its nominal detection probability to as low as $\sim 0.08$.

Station 4 displayed the greatest amount of noise at extreme distances, presumably due the restricted nature of the channel in which it was located and resultant tidally mediated current velocities (Fig. 9d). As such, data from this station are not likely to be representative of most locations at which acoustic gates would be placed; in particular, broader embayments and along the continental shelf. To determine whether a wider receiver spacing might be effective in quieter environments, the above calculations were conducted using data from the remaining stations, focusing on the $1200-\mathrm{m}$ transmitter nodes. Among these, the $0.5-\mathrm{m}$-elevation transmitter at Station 2 displayed the lowest detection proportion (i.e., 0.09). The MIL associated with transit of a gate with $1200-\mathrm{m}$ receiver spacing would be $1600 \mathrm{~m}$, and the probability that at least one tag identification would occur for a 100$\mathrm{cm}$ Pacific halibut swimming at constant cruising speed along that path, given a constant detection proportion of 0.09 , would be 0.884 .

\section{Discussion}

Range tests of acoustic transmitter-receiver combinations are advised, and often conducted as an initial step in research that is implemented to study the movements of mobile aquatic species [14, 15, 20,38]. We conducted our range tests in order to determine the feasibility of implementing movement studies using acoustic telemetry, attempting to determine the number of receivers that might be required to gate likely movement paths of sablefish and Pacific halibut. Ultimately, our focus was to determine the effort and costs that would be necessary to achieve detection efficiencies (i.e., recapture probability) sufficient to address questions regarding movement among management areas. Our results suggest that high fish-identification rates are likely for deepwater fish species crossing acoustic gates that are placed in waters up to $600 \mathrm{~m}$ in depth, with receivers spaced at up to $1200-\mathrm{m}$ distance from one another. However, striking temporal patterns in tag detection that were presumably related to oceanographic variability could markedly reduce detection probability on scales ranging from daily to seasonal and confound the interpretation of fish movement in 
some contexts. Thus, we strongly support recommendations to include sentinel tags in all active acoustic-tagging arrays (sensu [21]).

The detection range between acoustic receivers and transmitters can be influenced by a wide variety of factors. In addition to the characteristics of the transmitters (e.g., power, ping rate; $[39,40])$, these can include ambient noise levels (caused by current, waves, vessel traffic, or marine organisms), and wave bending that can be influenced by factors such as depth, temperature, and salinity gradients $[15,34,38,39]$, animal swimming speed [40], and physical obstructions between receivers and transmitters $[20,41]$.

\section{Considerations related to gear configuration}

Among the variety of factors that can influence tagdetection rates in deepwater environments, our results provide insight regarding the distance between receivers and transmitters, depth of transmitters relative to the sea surface, the relative elevation of transmitters off bottom, the potential effects of deploying transmitters in fixed orientations at fixed locations, and the likelihood of tag signal collisions when multiple tags broadcast in close proximity to one another. With respect to receiver-transmitter distances, of immediate concern is the degree to which we were able to place nodes within each array at their target distances. While we were unable to effectively use SYNAPS to verify node locations after placement, the data from Station 3 confirmed that lateral drift of the nodes during their descent to the sea floor might have introduced substantial variance into the nominally 200-m spacings that were intended. However, inspection of the resulting reception data suggests that this is unlikely to have had a large influence overall. Specifically, were the internode distances to vary broadly around the 200-m target, we would expect to have observed numerous cases in which the reception rates decayed discontinuously over the nominal distances. That is, it should have been common to observe cases in which adjacent nodes displayed nearly identical reception rates due to their close proximity to one another, followed by large stepwise decay at adjacent node(s) due to the artificially large internode distance(s) that would subsequently have resulted. At Station 4 there is evidence of this: the 600and 800-m nodes appear as if they were relatively close to one another based on nearly identical reception rates, while potentially having been being more distantly separated from the $400-$ and $1000-\mathrm{m}$ nodes, respectively. In a few other cases, there were "stutters" in the reception rates observed at single transmitter nodes, but not for both transmitter elevations as would be obligatory considering their attachment to the same mooring. Thus, considered among all stations and across the distances that defined their attenuation curves, we conclude that the nature of these results were unlikely to be substantially affected by node placement errors.

The percentages of total detections from transmitters other than those that we deployed were very small, ranging between 0.01 and $0.10 \%$ among the six receivers; therefore, collisions with transmitters other than ours were rather trivial. Similarly, although the transmitters deployed at each station transmitted constantly, increasing the chances for acoustic collisions among them, the peak reception rates observed at each station were consistently higher than the overall estimated rates derived from VEMCO's "Collision Calculator" (https://vemco. com/collision-calculator/). Whereas ten $\mathrm{V} 16-5 \mathrm{H}$ transmitters programmed as ours and broadcasting simultaneously in close proximity to one another would be expected to suffer a $27 \%$ signal-collision rate (i.e., $73 \%$ total detection rate), we observed detection rates that peaked at $74-82 \%$ among stations. Although some proportion of this relative difference would have been due to fewer signals reaching the receivers than expected, and therefore being unable to interfere with one another, these generally high peak reception rates argue against the hypothesis that code collisions were largely influential in the observed detection patterns. Additionally, our detection-to-ping ratios were relatively high. Detectionto-ping ratios in the range of $50-60 \%$ are common (D. Webber, VEMCO Limited, personal communication), whereas the mean daily ratios in this study ranged from 73 to $79 \%$. Positive noise quotients result from environmental noise that generates more pulses than could have been generated by tags [34]. Negative noise quotients, such as we experienced, are an indication of a high degree of signal collisions. Such high signal-collision rates should probably not be expected for free-ranging animals that only periodically come within range of receivers. As such, our tag-detection estimates are expected to be generally conservative.

Transmitters anchored in fixed positions may experience additional variations in detection rate that would be uncommon for transmitters attached to fish. With little or no current, our transmitters would have been oriented vertically in the water column, along the axis of their tethers. However, with increasing current the tethers would be pushed off vertical. In their study in a riverine system, Clements et al. [42] noted that acoustic power output was lower through the ends of transmitters relative to that which was produced around the sides of the cylinder. Thus, the orientation of the transmitter influences the direction of its greatest acoustic output. For a horizontally oriented tag implanted into a fish, maximum output would occur above and below the animal rather than off its nose and tail; i.e., the signal would be directed 
upwards toward the suspended receiver instead of along the seafloor. For our vertically oriented tags, their detectability was likely to vary as current conditions caused off-vertical fluctuations in their orientation, as well as changes in receiver angle. Additionally, sudden decreases in tag detection rate without later recovery (e.g., the nearbottom transmitter at the 1200-m node at Station 2, after February; see Fig. 5h) might occur if a tag breaks from its mooring, either in whole or in part.

Additionally, detection of our moored transmitters might decrease in cases where transmitters are depressed by currents to such an extent that a benthic object could occlude the path between the transmitter and receiver. Some of the consistently low detection rates that we observed (e.g., the near-bottom transmitter at the 800-m node at Station 2; see Fig. 5b) may have been attributable to a physical obstruction (e.g., kelp fronds) that partially blocked their transmission pathways. Again, such phenomena are less likely to affect tag-detection in mobile fish, as one would expect the animal to eventually swim past any obstruction and become detectable.

The pattern that was repeated at both offshore stations of decreased total detections from the 200-m transmitters relative to those at $400 \mathrm{~m}$ is also noteworthy. One possible reason for this could have been partial or periodic blocking of transmissions by the trawl floats used for transmitter suspension. For the transmitters positioned at $200 \mathrm{~m}$, the estimated angles to the receivers were approximately 18 and 16 degrees at Stations 5 and 6, respectively; for the 400-m transmitter nodes, these angles were about 9 and 8 degrees, respectively. Although these angles seem too low to place the trawl floats in direct lines between the transmitters and receivers, under unusually strong current conditions the floats could have been displaced sufficiently to have caused such interference. Alternatively, reduced detection of the tags closest to the receivers may have represented "close proximity detection interference" [43], in which signal decoding is prevented due to temporally overlapping detection of tag signals and their echoes emanating from reflective surfaces (e.g., the benthos, pycnoclines, or sea surface).

Finally, consistently higher tag-detection rates for the deeper receiver relative to the shallow receiver at Station 2, across transmitter-node distances and transmitter elevations, may be attributable to numerous factors, including relatively shorter linear distances from tag-totransmitter (i.e., slant distance; e.g., [44]), greater distance from surface-related acoustic noise, and greater distance from pycnoclines (see next section) that may interrupt or deflect signal transmissions. Alternatively, in habitats in which local topography might serve to block the transmission pathway between benthic transmitters and a suspended receiver, placing receivers higher in the water column could improve line of sight and increase detection probability relative to deeply deployed receivers. As such, for deep-dwelling fish, maximizing detection probabilities may involve a tradeoff between minimizing receiver-transmitter distances while maintaining effective line of sight.

\section{Environmental considerations}

Among the transient environmental factors that might affect tag-detection rates, daily averaged wind stress as a proxy for resulting sea state did not appear significant. Although others $[45,46]$ have concluded that wind stress can have a strong influence on acoustic tag detection, we could find no such effect on a daily scale. Differing results may be a function of the cited studies having deployed tags on mobile fauna as opposed to fixed moorings; or due the relatively deeper environments in which our tests took place. Alternatively, inconsistency in our results may have been caused by the nature of the wind data upon which we based our regressions. For most stations we were forced to use data from anemometer stations that were likely imperfect reflections of conditions at our test locations. Specifically, Bartlett Cove is a protected embayment located in the entrance to Glacier Bay, approximately $60 \mathrm{~km}$ north of Station 4; Port Alexander is located on the protected eastern side of Chichagof Island. As such, the wind stress estimates for all but Station 3 are likely to have been somewhat decoupled from the true conditions at the range-test stations. Furthermore, analyses based solely on daily mean wind speed will be naïve to relative persistence of those winds and the systems that generate them and, hence, the potential for sea state to build over extended periods without changes in mean stress. In contrast, the strong diurnal pattern that was apparent in the periodograms is wholly consistent with wind influence. Diurnal cycles in tag detection have been attributed to diurnal winds [46] and biological noise [15, 24]. Here, decreasing detection as days progressed and recovery of detection rates overnight suggest the building and relaxing of thermally driven diurnal winds [46, 47] in contrast to observations that biological noise tends to increase either at night [15] or crepuscularly [48].

The lack of strong evidence for tidal effects on tag detections was likely due to our deep operating depths, at which relatively low current speeds would be expected. Semmens et al. [27] conducted acoustic range tests over a monthly tide cycle in a flat-and-channel habitat that exhibited depths no greater than $40 \mathrm{~m}$ and found no relationship between tag-detection rates and either tidal phase (i.e., high, ebb, low, flood) or state (i.e., neap, intermediate, spring). In the current study, we did find evidence of the daily ebb-flood cycle via Fourier analysis (sensu [26]), but the signals were weak and the periods 
over which they occurred were transient. Although not indicated in the periodograms, closer attention to the hourly data from Station 4 suggested potentially strongest influence at the semilunar period. At this location, peak current velocities were expected to be $\geq 3 \mathrm{~cm} \mathrm{~s}^{-1}$ during spring tides and were probably capable of depressing transmitter and receiver floats, thereby changing angles of incidence associated with the transmissions. Inspection of the station's receiver revealed abrasions on its casing suggestive of having come into regular contact with the rocky bottom. Current has been shown to be among the factors that can impart rhythmic patterns in detection frequency (sensu Fig. 9), absent of tagged-animal behavior $[15,26]$.

Stratification of marine waters (i.e., pycnoclines: thermoclines and/or haloclines) can also influence the detectability of acoustic signals [26, 40]. Hydrographic structure of Southeast Alaskan waters is strongly influenced by seasonal precipitation, snow-melt, glacial runoff, and thermal forcing. We hypothesize that the stepwise, seasonal shifts in tag detection observed both within Frederick Sound (Stn. 3) and on the coastal shelf (Stns. 5 and 6), as well as the erosion of diurnal periodicity seen in the Fourier transforms, were influenced by such stratification. Strong seasonal shifts in the detectability of sentinel tags have been observed elsewhere (e.g., [26]), and in our case the onset of decreased detection was consistent with the expected development of summer pycnoclines. Conversely, downwelling, strong winds, and cooling serve to enhance vertical mixing [49] and probably contributed to the improved detectability in autumn and winter (e.g., Stn. 3, Fig. 6d, e). With respect to diurnal periodicity, we hypothesize that in summer the pycnocline may have served as a reflective surface that directed wave-generated surface noise back toward the receivers, amplifying its ability to interfere with transmitter signals. Erosion of this layer in winter would allow such noise to more efficiently disperse and attenuate to depth.

The source of 8-h periodicity in transmitter detections is more difficult to explain. We are unable to identify any obvious atmospheric, oceanographic, or anthropogenic factors that were likely to be operating in these areas during the study period. In theory, pronounced biological noise occurring at dawn and dusk (sensu [48]) should be capable of this at times when day length approximates $8 \mathrm{~h}$. However, in the study region this would occur from approximately November through January; the period over which no such periodicity was observed. Ultimately, additional studies in which corresponding environmental data are collected and measurements of ambient noise are conducted throughout the course of transmitter-receiver deployments may be required to identify the source of this signal.
Variation in tag detectability may also be attributable to factors such as varying, spatially complex bathymetry and shoreline configuration, passage constrictions, and the presence of sills; each of which can influence the direction and speed of wind, currents, salinity and temperature gradients, and vertical mixing. Finally, suspended sediments are known to influence acoustic transmissions [43]. Runoff from the coastal mountains of Southeast Alaska and glacial scouring introduce high particulate loads into the interior waters [49], in addition to the organically derived particulate load.

\section{Feasibility of deepwater acoustic gating}

Series of receivers may be oriented in linear arrays to form gates across pathways of known or suspected fish movements (e.g., [15, 38, 42]). Discrete estimates of detection probabilities can be used to quantify detection range, estimate appropriate spacing or density of receivers, and evaluate the utility of acoustic tagging as a method of addressing movement questions. Given the greatly varying and location-specific conditions that can influence detection probability, calculations such as those conducted herein should probably be conducted at each candidate location for acoustic gates or arrays.

Welsh et al. [20], working in a coral reef environment, concluded that the working detection range could be as low as $60 \mathrm{~m}$ for a VEMCO V9-1L transmitter with a power output of $146 \mathrm{~dB}$. Studying movement of blackspotted croaker (Protonibea diacanthus) Semmens et al. [27] used VEMCO VR2 receivers in concert with V16-5H transmitters (the same combination that we used) in two coastal areas of Australia. The areas included a channel that was $40-50 \mathrm{~m}$ deep bordered on each side by shallows $(5-10 \mathrm{~m})$, and a shallow $(<10 \mathrm{~m})$ muddy bay with rocky outcrops. They determined a maximum effective detection range of $200 \mathrm{~m}$, achieving 73-91\% detection. Studying cuttlefish (Sepia apama) in South Australia, Payne et al. [15] achieved a detection efficiency of about $46 \%$ at a distance of $200 \mathrm{~m}$ in water that was $6-10 \mathrm{~m}$ deep, using VEMCO V9AP-2L transmitters and VR2W receivers. Monitoring movements of Atlantic cod (Gadus morhua) in deep (65-100 m) boulder fields in the Gulf of Maine, Lindholm et al. [50] estimated a 400-m detection range for VEMCO V8SC-1H-R256 transmitters and VR2 receivers, based on $80 \%$ detection efficiency. Egli and Babcock [51] used VEMCO V16 and V8SC tags in combination VEMCO VR2 receivers on a coastal reef and determined a working range of $<500 \mathrm{~m}$.

Here, we estimated individual pairwise receiver-transmitter detection proportions that were no higher than 0.84 , but demonstrated that the probability of detecting a tagged fish moving through the gate could often be markedly higher, and a working detection range of $1000 \mathrm{~m}$ 
might be reasonable in many contexts. This would occur because the fish's transmitter would be expected to transmit multiple times while within the detection band, providing multiple opportunities for tag identification. In addition, the fish-identification probabilities that we estimated assumed that the fish would travel at a constant rate, along the shortest path possible, at maximum average distance from the receivers, with all of its tag transmissions spaced at the maximum nominal delay. This suite of assumptions is quite conservative, relative to a more likely scenario in which transmissions are more frequent and the instrumented fish travels a meandering path, thereby increasing its residence time and coming closer to the receivers than would be experienced by travelling along the MIL.

Pincock [52] suggests that, under worst-case conditions, $50 \%$ detection probability can be used as the limit for reliable tag detection. Among our range-test stations, this level was generally achieved at 1000-1200 m from the receivers, potentially allowing for a high probability of fish identification using $2000-2400 \mathrm{~m}$ spacing in the areas where we would be likely to establish acoustic gates. This spacing might be insufficient to yield precise estimates of movement rates in applications where such estimates would directly impact quota decisions, and maintaining substantially closer spacing (e.g., $1000 \mathrm{~m}$ ) may be financially prohibitive across large segments of continental shelf. For example, it may be infeasible to gate the borders between British Columbia and the USA, from shore to 1000-m depth, in order to estimate seasonal biomass redistribution [8] relative to fishery opening and closing dates (sensu [53]). However, using acoustic tagging to address questions that are less rate-dependent appears feasible. For example, the technology could be appropriate for estimating proportional redistribution among areas and for elucidating the timing of dispersal of various demographics within both Pacific halibut and sablefish populations. The receiver spacings that proved viable here are similar to those used by Pecl et al. [40] to study movements of calamary (Sepioteuthis australis) in inshore waters of Tasmania and may prove feasible for gating ecologically important deepwater features of the North Pacific, for example, passes of the Aleutian Island Chain in order to assess the relative isolation of local halibut spawning groups (sensu $[54,55]$ ), or the continental shelf west of Vancouver Island to investigate relationships between sablefish dispersal and environmental forcing functions (sensu [2]). Ultimately, the utility of any technological advancement should be assessed relative to the scale of the questions that are to be addressed. Acceptable detection thresholds will be case-specific and should be evaluated in the context of acceptable levels of failure to detect instrumented animals moving through the chosen array.

\section{Conclusions}

Our range tests indicate that relatively high fish-identification probabilities (i.e., $\geq 90 \%$ ) of deepwater (i.e., up to 600-m water depth) targets can be achieved using V16$\mathrm{H} 5$ transmitters in combination with VEMCO VR2W receivers that are spaced up to $2400 \mathrm{~m}$ apart, for example, in linear arrays or gates. The variation in tag-detection proportions that we experienced suggests that periodic oceanographic and atmospheric conditions can alter tagdetection probabilities-potentially to a large degreeat a variety of behaviorally and ecologically important scales, and so range testing should be conducted at all geographic locations at which receiver arrays are to be established rather than simply testing at a few locations and extrapolating among locations. Furthermore, operational arrays should contain sentinel tags, to monitor detection rates and account for transient features that may affect those rates. These considerations may be particularly relevant when multiple arrays are established over large geographic areas, invoking a complex of spatial and temporal factors that can influence detectability. Finally, it should be noted that linear acoustic gates can provide important information about fish movement, but can only provide evidence that a tagged individual has come within the gate's detection range $[14,40]$. No array can provide definitive proof that any tagged animal has moved beyond the array. To substantiate passage through an array or gate, the animal must be detected at a subsequent array located at an appropriate distance beyond the first. This potential need for multiple gates to verify dispersal among areas should be considered when designing acoustic networks to address movementrelated hypotheses.

\section{Abbreviations}

IPHC: International Pacific Halibut Commission; NMFS: US National Marine Fisheries Service; PIT: passive integrated transponder; Stn: station; Stns: stations; SYNAPS: synthetic aperture positioning system; MIL: minimum intersection line.

\section{Authors' contributions}

DC participated in study design, coordinated vessel logistics and conducted gear deployment and recovery, data retrieval and analysis, and generated the first draft of the manuscript. TL participated in study design, oversaw gear construction, participated in gear deployment, data analysis, and undertook manuscript revisions. All authors read and approved the final manuscript.

\section{Author details}

${ }^{1}$ International Pacific Halibut Commission, 2320 W. Commodore Way, Suite 300, Seattle, WA 98199-1287, USA. ${ }^{2}$ Division of Commercial Fisheries, Alaska Department of Fish and Game, P.O. Box 115526, 1255 W. 8th St., Juneau, AK 99811-5526, USA. 


\section{Acknowledgements}

Andy Vatter, John Eiler, Julie Nielsen, and Cindy Tribuzzio contributed valuable input for research planning and participated in the initial deployment cruise. Chris Lunsford contributed valuable scientific input and administrative support during research planning. Bruce Leaman provided valuable input during study design, analysis, and manuscript preparation. Vessel crews aboard the RN Medeia and FN Seaview provided support during deployment and recovery cruises. Adam Lipper provided technical support during our second cruise, for receiver recovery and additional deployments.

David Carlile is retired from Alaska Department of Fish and Game.

\section{Competing interests}

The authors declare that they have no competing interests.

\section{Availability of data and materials}

All datasets generated during the current study and in the possession of the International Pacific Halibut Commission (IPHC) are protected by the International Organizations Immunity Act, 22 U.S.C. Sec 288 et seq. Individuals interesting in obtaining any of these data may contact the corresponding author to obtain procedures for submitting a data request to the IPHC.

\section{Consent for publication}

Not applicable.

\section{Ethics approval and consent to participate} Not applicable.

\section{Funding}

Financial support for this research was provided by the Alaska Department of Fish and Game, the International Pacific Halibut Commission, the US National Marine Fisheries Service, and the Pacific Ocean Shelf Tracking (P.O.S.T.) Project. While officials at the funding agencies provided guidance with respect to the type of information that they would consider most useful for the implementation of future acoustic monitoring arrays, all aspects of study design, data collection, and the analysis and interpretation of these data rest solely with the authors.

\section{Publisher's Note}

Springer Nature remains neutral with regard to jurisdictional claims in published maps and institutional affiliations.

Received: 27 July 2016 Accepted: 20 November 2017

Published online: 11 December 2017

\section{References}

1. Hanselman DH, Heifetz J, Echave KB, Dressel SC. Move it of lose it: movement and mortality of sablefish tagged in Alaska. Can J Fish Aquat Sci. 2015;72:238-51. https://doi.org/10.1139/cjfas-2014-0251.

2. Heifetz J, Fujioka JT. Movement dynamics of tagged sablefish in the northeastern Pacific. Fish Res. 1991;11:355-74. https://doi. org/10.1016/0165-7836(91)90009-5.

3. Kimura DK, Shimada AM, Shaw FR. Stock structure and movement of tagged sablefish, Anoplopoma fimbria, in offshore northeast Pacific waters and the effects of El Niño-Southern Oscillation on migration and growth. Fish Bull. 1998;96:462-81.

4. Bracken BE. Sablefish (Anoplopoma fimbria) migration in the Gulf of Alaska based on gulf-wide tag recoveries, 1973-1981. Alaska Department of Fish and Game, Juneau; 1982. Informational Leaflet No.: 199.

5. Baldwin A, Stahl J. 2013 NSEl (Northern Southeast Inside Subdistrict) Sablefish Mark-Tag Survey. Alaska Department of Fish and Game, Juneau; 2014. Fishery Data Series No.: 14-27.

6. Webster RA, Clark WG, Leaman BM, Forsberg JE. Pacific halibut on the move: a renewed understanding of adult migration from a coastwide tagging study. Can J Fish Aquat Sci. 2013;70:642-53. https://doi. org/10.1139/cjfas-2012-0371.
7. Clark W, Hare SR. Motivation and plan for a coastwide stock assessment In: Sadorus L, editor. Report of assessment and research activities, 2006. Seattle: International Pacific Halibut Commission; 2007. p. 82-94.

8. Leaman BL, Geernaert TO, Loher T, Clark WG. Further examination of biological issues concerning an extended commercial fishing season. In: Sadorus L, editor. Report of assessment and research activities, 2001. Seattle: International Pacific Halibut Commission; 2002. p. 53-73.

9. Loher T. Analysis of match-mismatch between commercial fishing periods and spawning ecology of Pacific halibut (Hippoglossus stenolepis), based on winter surveys and behavioural data from electronic archival tags. ICES Mar Sci. 2011;68:2242-53. https://doi.org/10.1093/icesjms/ fsr152.

10. Hoenig JM, Barrowman NJ, Hearn WS, Pollock KH. Multiyear tagging studies incorporating fishing effort data. Can J Fish Aquat Sci. 1998;55:146676. https://doi.org/10.1139/f97-256.

11. Waterhouse L, Hoenig JM. Tagging models for estimating survival rates when tag visibility changes over time: partial-year tabulation of recaptures. N Am J Fish Manag. 2012;32:147-58. https://doi.org/10.1080/02755 947.2012.661383.

12. Meyer KA, Elle FS, Lamansky JA, Mamer ERJM, Butts AE. A reward-recovery study to estimate tagged-fish reporting rates by ldaho anglers. N Am J Fish Manag. 2012:32:696-703. https://doi.org/10.1080/02755947.2012.685142.

13. Waterhouse L, Hoenig JM. Instantaneous-rates models allowing for delayed mixing of newly tagged cohorts: partial year tabulation of recaptures. N Am J Fish Manag. 2011;31:995-1004. https://doi.org/10.1080/027 55947.2011.633685.

14. Heupel ME, Semmens JM, Hobday AJ. Automated acoustic tracking of animals: scales, design and deployment of listening station arrays. Mar Freshw Res. 2006:57:1-13. https://doi.org/10.1071/MF05091.

15. Payne NL, Gillanders BM, Webber DM, Semmens JM. Interpreting diel activity patterns from acoustic telemetry: the need for controls. Mar Ecol Prog Ser. 2010;419:295-301. https://doi.org/10.3354/meps08864.

16. Mecklenburg CW, Mecklenburg TA, Thorsteinson LK. Fishes of Alaska. Bethesda: American Fisheries Society; 2002.

17. Hare SR, Webster RA, Leaman BL, Dykstra CL. Discussion paper on IPHC setline survey expansion. In: Sadorus L, editor. Report of assessment and research activities, 2010. Seattle: International Pacific Halibut Commission; 2011. p. 201-17.

18. Seitz AC, Loher T, Nielsen JL. Seasonal movements and environmental conditions experienced by Pacific halibut in the Bering Sea, examined by pop-up satellite tags. International Pacific Halibut Commission, Seattle; 2007. Scientific report no. 84

19. Huveneers C, Simpfendorfer CA, Kim S, Semmens JM, Hobday AJ, Pedersen $H$, Stiegletz T, Vallee R, Webber D, Heupel MR, Peddermons V, Harcourt RG. The influence of environmental parameters on the performance and detection range of acoustic receivers. Methods Ecol Evol. 2016. https://doi.org/10.1111/2041-210X.12520.

20. Welsh JQ, Fox RJ, Webber DM, Bellwood DR. Performance of remote acoustic receivers within a coral reef habitat: implications for array design. Coral Reefs. 2012;31:693-702. https://doi.org/10.1007/s00338-012-0892-1.

21. Kessel ST, Cooke SJ, Heupel MR, Hussey NE, Simpfendorfer CA, Vagle S, Fisk AT. A review of detection range testing in aquatic passive acoustic telemetry studies. Rev Fish Biol Fish. 2013;24:199-218. https://doi. org/10.1007/s11160-013-9328-4.

22. Andrews KS, Tolimieri N, Williams GD, Samhouri JF, Harvey CJ, Levin PS, Comparison of fine-scale acoustic monitoring systems using home range size of a demersal fish. Mar Biol. 2011;158:2377-87. https://doi. org/10.1007/s00227-011-1724-5.

23. Shroyer SM, Lodsdon DE. Detection distances of selected radio and acoustic tags in Minnesota lakes and rivers. N Am J Fish Manag. 2009;29:876-84. https://doi.org/10.1577/M08-189.1.

24. How JR, de Lestang S. Acoustic tracking: issues affecting design, analysis and interpretation of data from movement studies. Mar Freshw Res. 2012;63:312-24. https://doi.org/10.1071/MF11194.

25. Singh L, Downey NJ, Rogerts MJ, Webber DM, Smale MJ, van den Berg MA, Harding RT, Engelbrecht DC, Blows BM. Design and calibration of an acoustic telemetry system subject to upwelling events. Afr J Mar Sci. 2009:31:355-64. https://doi.org/10.2989/AJMS.2009.31.3.8.996.

26. Mathies NH, Ogburn MB, McFall G, Fangman S. Environmental interference factors affecting detection range in acoustic telemetry studies 
using fixed receiver arrays. Mar Ecol Prog Ser. 2014;495:27-38. https://doi. org/10.3354/meps 10582 .

27. Semmens JM, Buxton CD, Forbes E, Phelan MJ. Spatial and temporal use of spawning aggregation sites by the tropical sciaenid Protonibea diacanthus. Mar Ecol Prog Ser. 2010;403:193-203. https://doi.org/10.3354/ meps08469.

28. Espinoza M, Farruigia TJ, Webber DM, Smith F, Lowe CG. Testing a new acoustic telemetry technique to quantify long-term, fine-scale movements of aquatic animals. Fish Res. 2011;108:364-71. https://doi org/10.1019/j.fishres.2011.01.011.

29. Starr RM, O'Connell V, Ralston S, Breaker L. Use of acoustic tagging to estimate natural mortality, spillover, and movements of lingcod (Ophiodon elongatus) in a marine reserve. Mar Technol Soc J. 2005;39:19-30. https:// doi.org/10.4031/002533205787521677.

30. Starr RM, Heine JN, Johnson KA. Techniques for tagging and tracking deepwater rockfishes. N Am J Fish Manag. 2000;20:597-609. https://doi. org/10.1577/1548-8675(2000)020<0597:TFTATD > 2.3.CO;2.

31. Davis B, VanderZwaag DL, Cosandrey-Godin A, Hussey NE, Kessel ST, Worm B. The conservation of the Greenland shark (Somniosus microcephalus): setting scientific, law, and policy coordinates for avoiding a species at risk. J Int Wildl Law Policy. 2013;39:19-30. https://doi.org/10.1081/1388 0292.2013.805073.

32. Stokesbury MJW, Harvey-Clark C, Gallant J, Block BA, Myers RA. Movement and environmental preferences of Greenland sharks (Somniosus microcephalus) electronically tagged in the St. Lawrence Estuary, Canada. Mar Biol. 2005;148:159-65. https://doi.org/10.1007/s00227-005-0061-y.

33. Nielsen JK, Niezgoda GH, Taggart SJ, Cooke SJ, Anson P, Hasler CT, Hanson KC, Carl G. Mobile positioning of tagged aquatic animals using acoustic telemetry with a synthetic hydrophone array (SYNAPS: synthetic aperture positioning system). In: McKenzie J, Parsons B, Seitz A, Mesa M, Kopf RK, Phelps Q, West K, editors. Advances in fish tagging and marking technology. Bethesda: American Fisheries Society; 2012. p. 233-50.

34. Simpfendorfer CA, Heupel MR, Collins AB. Variation in the performance of acoustic receivers and its implications for positioning algorithms in a riverine setting. Can J Fish Aquat Sci. 2008;65:482-92. https://doi. org/10.1139/f07-180.

35. Brown J, Colling A, Park D, Phillips J, Rothery D, Wright J. Ocean circulation. New York: Pergamon; 1989.

36. R Development Core Team. R: a language and environment for statistical computing. The R Foundation, Vienna; 2013. https://www.r-project.org. Accessed 03 June 2017.

37. Radziwill NM. Statistics (the easier way) with R. San Francisco: Lapis Lucera; 2015.

38. Domeier ML. Methods for the deployment and maintenance of an acoustic tag tracking array: an example from California's Channel Islands. Mar Technol Soc J. 2005;39:74-80. https://doi. org/10.4031/002533205787521668.

39. Simpfendorfer CA, Heupel MR, Heuter RE. Estimation of short-term centers of activity from an array of omnidirectional hydrophones and its use in studying animal movements. Can J Fish Aquat Sci. 2002;59:23-32. https://doi.org/10.1139/f01-191.

40. Pecl GT, Tracey SR, Semmens JM, Jackson GD. Use of acoustic telemetry for spatial management of southern calamary Sepioteuthis australis, a highly mobile inshore squid species. Mar Ecol Prog Ser. 2006;328:1-15. https://doi.org/10.3354/meps328001.

41. Lindholm J, Knight A, Kaufman L, Miller S. Site fidelity and movement of the parrotfishes Scarus coeruleus and Scarus taeniopterus at Conch Reef (northern Florida Keys). Caribb J Sci. 2006;42:138-44.
42. Clements S, Jepsen D, Karnowski M, Schreck CB. Optimization of an acoustic telemetry array for detecting transmitter-implanted fish. N Am J Fish Manag. 2005;25:429-36. https://doi.org/10.1577/M03-224.1.

43. Kessel ST, Hussey NE, Webber DW, Gruber SH, Young JM, Smale MJ, Fish AT. Close proximity detection interference with acoustic telemetry: the importance of considering tag power output in low ambient noise environments. Anim Biotelem. 2015;3:5. https://doi.org/10.1 186/ s40317-015-0023-1.

44. Marques TA, Thomas L, Ward J, DiMarzio N, Tyack PL. Estimating cetacean population density using passive acoustic sensors: an example with Blainville's beaked whales. J Acoust Soc Am. 2009;125:1982-94. https:// doi.org/10.1121/1.3089590.

45. Baker LL, Jonsen ID, Mills Flemming JE, Lidgard DC, Bowen WD, Iverson SJ, Webber DM. Probability of detecting marine predator-prey and species interactions using novel hybrid acoustic transmitter-receiver tags. PLoS ONE. 2014;9:e98817. https://doi.org/10.1371/journal.pone.0098117.

46. Gjelland $K \varnothing$, Hedger RD. Environmental influence on transmitter detection probability in biotelemetry: developing a general model of acoustic transmission. Methods Ecol Evol. 2013;4:665-74. https://doi.org/10.1111/ 2041.210X.12057.

47. Lindzen RS. Thermally driven diurnal tide in the atmosphere. Q J R Meteorol Soc. 1967;93:18-42. https://doi.org/10.1002/qj.49709339503Koeck.

48. March D, Palmer M, Alós J, Grau A, Cardona F. Short-term residence, home range size and diel patterns of the painted comber Serranus scriba in a temperate marine reserve. Mar Ecol Prog Ser. 2010;400:195-206. https:// doi.org/10.3354/meps0841.

49. Weingartner T, Eisner L, Eckert GL, Danielson S. Southeast Alaska: oceanographic habitats and linkages. J Biogeogr. 2009;36:387-400. https://doi. org/10.1111/j.1365-2699.2008.01994.x.

50. Lindholm J, Auster PJ, Knight A. Site fidelity and movement of adult Atlantic cod Gadus morhua at deep boulder reefs in the western Gulf of Maine, USA. Mar Ecol Prog Ser. 2007;342:239-47. https://doi.org/10.3354/ meps342239.

51. Egli DP, Babcock RC. Ultrasonic tracking reveals multiple behavioural modes of snapper (Pagrus auratus) in a temperate no-take marine reserve. ICES J Mar Sci. 2004;61:1137-43. https://doi.org/10.1016/j. icesjms.2004.07.004.

52. Pincock DG. Detection performance of lines of VR2W/VR3 receivers. Amirix Systems, Halifax; 2009. DOC-004819 Version 01.

53. Loher T, Blood CL. Seasonal dispersion of Pacific halibut (Hippoglossus stenolepis) summering off British Columbia and the US Pacific Northwest evaluated via satellite archival tagging. Can J Fish Aquat Sci. 2009;66:1409-22. https://doi.org/10.1139/f093.

54. Seitz AC, Loher T, Nielsen JL. Seasonal movements and environmental conditions experienced by Pacific halibut along the Aleutian Islands, examined by pop-up satellite tags. International Pacific Halibut Commission, Seattle; 2008. Scientific report no. 85.

55. Loher T, Clark W. Deployment, recovery, and reporting of pop-up archival transmitting (PAT) tags to study interannual dispersal and seasonal migration timing in IPHC Regulatory Area 4. In: Sadorus L, editor. Report of assessment and research activities, 2009. Seattle: International Pacific Halibut Commission; 2010. p. 537-51.

\section{Submit your next manuscript to BioMed Central and we will help you at every step:}

- We accept pre-submission inquiries

- Our selector tool helps you to find the most relevant journal

- We provide round the clock customer support

- Convenient online submission

- Thorough peer review

- Inclusion in PubMed and all major indexing services

- Maximum visibility for your research

Submit your manuscript at www.biomedcentral.com/submit 